\title{
Molten Salt Reactor Neutronics and Fuel Cycle Modeling and Simulation with SCALE
}

\author{
Benjamin R. Betzler*, Jeffrey J. Powers, Andrew Worrall
}

Oak Ridge National Laboratory: Building 5700, Room J301, Mail Stop 6172; Oak Ridge

National Laboratory, Oak Ridge, TN 37831

"Corresponding author: betzlerbr@ornl.gov

\begin{abstract}
Current interest in advanced nuclear energy and molten salt reactor (MSR) concepts has enhanced interest in building the tools necessary to analyze these systems. A Python script known as ChemTriton has been developed to simulate equilibrium MSR fuel cycle performance by modeling the changing isotopic composition of an irradiated fuel salt using SCALE for neutron transport and depletion calculations. Improved capabilities in ChemTriton include a generic geometry capable of modeling multi-zone and multi-fluid systems, enhanced time-dependent feed and separations, and a critical concentration search. Although more generally applicable, the capabilities developed to date are illustrated in this paper in three applied problems: (1) simulating the startup of a thorium-based MSR fuel cycle (a likely scenario requires the first of these MSRs to be started without available ${ }^{233} \mathrm{U}$ ); (2) determining the effect of the removal of different fission products on MSR operations; and (3) obtaining the equilibrium concentration of a mixed-oxide light-water reactor fuel in a two-stage fuel cycle with a sodium fast reactor. The third problem is chosen to demonstrate versatility in an application to analyze the fuel cycle of a non-MSR system.

In the first application, the initial fuel salt compositions fueled with different sources of fissile material are made feasible after (1) removing the associated nonfissile actinides after much of the

This manuscript has been authored by UT-Battelle, LLC under Contract No. DE-AC05-00OR22725 with the U.S. Department of Energy. The United States Government retains and the publisher, by accepting the article for publication, acknowledges that the United States Government retains a non-exclusive, paid-up, irrevocable, world-wide license to publish or reproduce the published form of this manuscript, or allow others to do so, for United States Government purposes. The Department of Energy will provide public access to these results of federally sponsored research in accordance with the DOE Public Access Plan (http://energy.gov/downloads/doe-public-access-plan ).
\end{abstract}


initial fissile isotopes have burned and (2) optimizing the thorium concentration to maintain a critical configuration without significantly reducing breeding capability. In the second application, noble metal, volatile gas, and rare earth element fission products are shown to have a strong negative effect on criticality in a uranium-fueled thermal-spectrum MSR; their removal significantly increases core lifetime (by 30\%) and fuel utilization. In the third application, the fuel of a mixed-oxide light-water reactor approaches an equilibrium composition after 20 depletion steps, demonstrating the potential for the longer time scales required to achieve equilibrium for solid-fueled systems over liquid fuel systems. This time to equilibrium can be reduced by starting with an initial fuel composition closer to that of the equilibrium fuel, reducing the need to handle time-dependent fuel compositions.

Key Words: Molten salt reactors, fuel cycle, depletion, salt treatment, salt separations.

\section{Introduction}

In a liquid-fueled molten salt reactor (MSR), the molten salt fuel is continuously circulated through the core. The salt undergoes irradiation, chemical treatments and separations, and feeds (fueling) simultaneously. This presents a challenge for modern neutron transport and depletion tools designed for analysis of solid-fueled systems, where the fission products, actinides, and activated isotopes physically remain within a fuel rod or assembly. Previous analysis of liquid-fueled MSRs has largely focused on the state of the reactor at an equilibrium condition after fission products have built up in the fuel salt over years of operation. Many designs either account for fission product and transuranic buildup in key metrics (Bulmer et al., 1956; Smith and Simmons, 1974) or use some calculated equilibrium fission product concentration for neutron balance (Robertson et al., 1970; 
Robertson et al., 1971; Taube and Ligou, 1974; Taube, 1974; Mourogov and Bokov, 2006). Little analysis has focused on the way the isotopic composition of the fuel salt changes from the startup of an MSR until this equilibrium condition.

The recent $\$ 1.3$ billion in private investment in advanced reactor technology detailed in a Third Way report (Brinton, 2016) includes several liquid-fueled MSR concepts; this provides a growing need for MSR neutronics and fuel cycle tools (along with additional MSR transient and heat transfer analysis tools). Increased interest in advanced reactors resulted in White House meetings on the topic (White House, 2015), the formation of the Gateway for Accelerated Innovation in Nuclear (US DOE, 2015), and laboratory partnerships on FOA awards (US DOE, 2016). Additional interest in advanced reactors from regulatory bodies is a natural consequence of this heavy investment from the private sector.

While there is no established liquid-fueled MSR tool for neutronics and fuel cycle design and evaluation, there are products from universities, research institutions, and internally developed tools that use methods similar to those used in the work discussed in this paper (Serp et al., 2014). The groundwork for these tools was laid during the early MSR programs at Oak Ridge National Laboratory (ORNL), which integrated neutronic and fuel cycle analysis tools (Bauman et al., 1971) into processing plant codes (Kee and McNeese, 1976) for MSR and processing system design work. More recent efforts in Europe and Asia focus on fast spectrum system fuel cycle analysis and use some framework to couple neutron transport and depletion codes to account for the continuous feeds and removals in MSRs for fuel cycle analysis. A sample of four of these efforts shows the depth and range of these methods: 
(1) MCNP (MCNP) neutron transport with REM (Heuer et al., 2010), a specialized material evolution tool (Nuttin et al., 2005; Doligez et al., 2014; Heuer et al., 2014),

(2) ERANOS (Rimpault et al., 2002) for neutron transport and depletion (Fiorina el al., 2013),

(3) KENO-VI (Goluoglu et al., 2011) neutron transport with ORIGEN (Gauld et al., 2011) depletion (Sheu et al. 2013), and

(4) SERPENT-2 (SERPENT) for neutron transport and depletion (Aufiero et al., 2013).

Though some of these methods are applicable to thermal systems, there are additional tools developed specifically for thermal MSR applications:

(5) MCODE (Xu et al., 2002), which uses MCNP neutron transport with ORIGEN2 (Ludwig and Renier, 1989) depletion in applications (Ahmad et al., 2015) to the denatured molten salt reactor (DMSR), (Engel et al., 1980), and

(6) MCNP6 neutron transport with CINDER90 (MCNP6) depletion in applications to whole core (Park et al., 2015) and multi-zone (Jeong et al., 2016) MSR modeling and simulations. Some of these methods provide some form of reactivity control $(1,3,4)$, use a set of all nuclides in depletion calculations $(1,4,5,6)$, or provide for true continuous feeds and removals $(1,4)$. The works described in (3) and (6) are most similar to the work presented in this paper. This discussion is not intended to be exhaustive but is representative of the current state-of-the-art. Note that there exist internally developed tools that are not discussed in the open literature.

The objective of the work herein is to analyze MSR systems and fuel cycles in support of the Fuel Cycle Options Campaign of the US Department of Energy, Office of Nuclear Energy (DOE-NE). The DOE-NE chartered a study to conduct an evaluation and screening of nuclear fuel cycle options. This Evaluation and Screening Study (E\&S) provides information about the potential 
benefits and challenges of nuclear fuel cycle options (i.e., the complete nuclear energy system from mining to disposal). This information is intended to strengthen the basis and provide guidance for the activities undertaken by the DOE-NE Fuel Cycle Research and Development program (Wigeland et al., 2014). The results of the E\&S and follow-on studies have yielded several significant peer-reviewed contributions in the literature. One vital contribution is a review of the impact of various nuclear fuel cycles on nuclear waste management metrics (Stauff et al., 2015). This provides an overview of the nuclear waste management metrics performance of each of the fuel cycles in the E\&S, as well as an overview of the nuclear waste management metrics themselves, which are important for the fuel cycle analysis of MSRs. Other literature related to or reviewing the E\&S has explored performance trade-offs in various sustainable fuel cycles by examining the impact of technology choices (Brown et al., 2015), assessed performance of externally driven systems versus critical reactors (Heidet et al., 2015; Brown et al., 2016a), and examined the transition from the present once-through fuel cycle to a potential future fuel cycle (Feng et al., 2016; Brown et al., 2016b). This transition analysis is similar to an application presented herein.

This paper discusses the development and applications of ChemTriton, a modeling and simulation tool originally developed for MSR analysis using SCALE (Bowman, 2011) for neutron transport and depletion calculations. This tool builds on previous efforts at ORNL in MSR modeling and simulation tool development (Powers et al., 2013) and applications (Powers et al., 2014; Brown et al., 2015; Betzler et al., 2016; Gehin and Powers, 2016). The development approach focused on producing a generic and flexible tool to give ChemTriton the ability to perform fuel cycle analysis as well as simulate a variety of liquid-fueled systems. 


\section{Methods Development}

Modeling liquid-fueled systems with current neutron transport and depletion tools is challenging because most of these tools are designed for analyzing the solid-fueled systems that represent the entire world-wide commercial reactor fleet. Two main challenges are presented by liquid-fueled systems: (1) the fuel material flows and (2) potential online separations or feeds of specific elements or isotopes. ChemTriton accounts for online separations and feeds using SCALE neutron transport and depletion tools.

\subsection{Fuel Material Flow}

Fuel flow is important due to delayed neutron emission. In a solid-fueled reactor, the fission product delayed neutron precursors remain very close to the fission site where they are created, later emitting delayed neutrons at that location. Delayed neutrons are emitted with a softer energy spectrum than prompt neutrons. The precursors drift when the fuel flows; the fission site and the location of delayed neutron emission are different. The reactor design determines the effect of this precursor drift on core physics; the fuel may flow out of the core to a heat exchanger, or may only be free to circulate within a control volume. The flow characteristics (e.g., flow rate, flow loop size, pipe diameter, etc.) affect $\beta_{\text {eff }}$, the effective delayed neutron fraction. This quantity has reactor safety implications because delayed neutron production occurs on a large enough time scale to allow a reactor to be controlled.

Accounting for precursor drift is vital for time-dependent analysis of MSRs and reactor safety. The earliest developments for dynamic analysis of MSRs come out of the MSR programs at ORNL 
(Kerlin et al., 1971). More recent efforts have generated system analysis tools (Shi et al., 2016), reactor dynamics tools (Cammi et al., 2012), safety analysis tools (Shimazu, 1978), and complex 3D coupled neutronic-thermal hydraulic tools (Křepel et al., 2007; Křepel et al., 2008; Kópházi et al., 2009; Zhou et al., 2015), all tailored to liquid-fueled MSRs. Additional recent work on fast-spectrum molten salt reactors have yielded transient tools (Fiorina et al., 2014) and methods developments for calculating the effective delayed neutron fraction of fluid-fueled systems (Aufiero et al., 2014).

From a fuel cycle perspective, precursor drift affects depletion calculations by augmenting the energy spectrum and strength of the neutron source within the core. Accounting for this drift requires a correction factor or the addition of a convection term to the neutron transport equation (Cheng and Dai, 2014). ChemTriton does not currently account for delayed neutron precursor drift; this work focuses on simulating online separations and feeds.

\subsection{Online Separations and Feeds}

A liquid-fueled reactor is likely to have online separations and/or feeds, where material is moved to or from the core at all times (continuous) or at specific intervals (batch). In a solid-fueled reactor, fission products and actinides remain within the initial fuel material during and after operation until reprocessing (or indefinitely in a once-through fuel cycle). The ability to perform online separations improves the potential neutronic performance of liquid-fueled systems. For example, it is unnecessary for liquid-fueled systems to operate with excess reactivity if fissile material is continuously being fed into the core. There is also an additional neutronic benefit from removing fission products with high concentrations and absorption cross sections, but removal of 
each element from the liquid fuel presents a unique issue in terms of storage and disposal of the separated materials.

To account for batch discards, a depletion tool must have the ability to remove a fraction or total amount of a material at a specified time. This requires the simulation to stop at a given time and restart with a new liquid fuel composition (after the removal of discarded materials). Accounting for a continuous removal or addition is more difficult because it requires adding a term to the Bateman equations. In SCALE/TRITON (Transport Rigor Implemented with Time-Dependent Operation for Neutronic Depletion) (DeHart and Bowman, 2011), ORIGEN (Oak Ridge Isotope Generation)

(Gauld et al., 2011) solves a set of Bateman equations using spectrum-averaged (i.e., one-group) fluxes and cross sections provided from a transport calculation. These equations describe the rate of change of the nuclides in the problem, where the rate of change of nuclide $i$ is:

$$
\frac{d N_{i}}{d t}=\sum_{j=1}^{m} l_{i j} \lambda_{j} N_{j}+\bar{\Phi} \sum_{k=1}^{m} f_{i k} \sigma_{k} N_{k}-\left(\lambda_{i}+\bar{\Phi} \sigma_{i}+r_{i}\right) N_{i}
$$

where $N_{i}, N_{j}, N_{k}$, and are the number densities of nuclides $i, j$, and $k$;

$l_{i j}$ is the branching fractions of radioactive decay from nuclide $j$;

$\lambda_{i}$ and $\lambda_{j}$ are the decay constants of nuclides $i$ and $j$;

$\bar{\Phi}$ is the space- and energy-averaged neutron flux;

$f_{i k}$ is the branching fraction for neutron absorption by other nuclides $k$ that lead to the formation of nuclide $i$;

$\sigma_{i}$ and $\sigma_{k}$ are the spectrum-averaged neutron absorption cross sections of nuclides $i$ and $k$; and $r_{i}$ is the external loss constant for nuclide $i$. 
The three terms on the right-hand side of the equation represent (1) the decay rate of nuclide $i$ into nuclide $j,(2)$ the production rate of nuclide $i$ from irradiation, and (3) the loss rate of nuclide $i$ due to decay, irradiation, or other means. For a solid-fueled reactor, $r_{i}$ is zero. SCALE/TRITON does not allow specification of non-zero removal or feed rates for depletion simulations, though ORIGEN input allows the specification of these rates. For ORIGEN, these rates must be expressed in terms of a decay constant, and an accurate removal/feed rate must take into account liquid fuel flow rates and reactor design. Instead of using this approach, ChemTriton uses a semi-continuous batch process to simulate a continuous process.

A script has been developed by T. J. Harrison, ORNL, to model the changing isotopic composition of an MSR molten fuel salt during reactor operation (Powers et al., 2013). This tool models salt treatment, separations, discards, and fueling using an MSR unit cell model, iteratively running SCALE/TRITON over small time steps to simulate continuous processes and deplete the fuel salt. More details are available in (Powers et al., 2013); the focus of this paper is to describe the extensions to this methodology.

\subsection{The ChemTriton Modeling and Simulation Tool}

The objectives were to expand on earlier ORNL efforts for modeling MSRs (Powers et al., 2013) and provide a more generic tool for the modeling and simulation of systems where material is removed or added at any time during irradiation. First, the original script was converted into an object-oriented Python script (van Rossum, 1995) named ChemTriton, which was then fully benchmarked against previous solutions obtained with the original script. Several features were added to ChemTriton to perform analyses on a variety of MSR designs, including use of a generic 
external input file for SCALE/TRITON; SCALE standard composition reading and writing; post-processing tools to list isotopic, flux, and four factor information during operation; multiple irradiation zone capabilities; time-dependent fuel feed and isotopic separations; and critical concentration search capabilities. ChemTriton maintains the iterative approach to the simulation of continuous feeds and removals (Fig. 1).

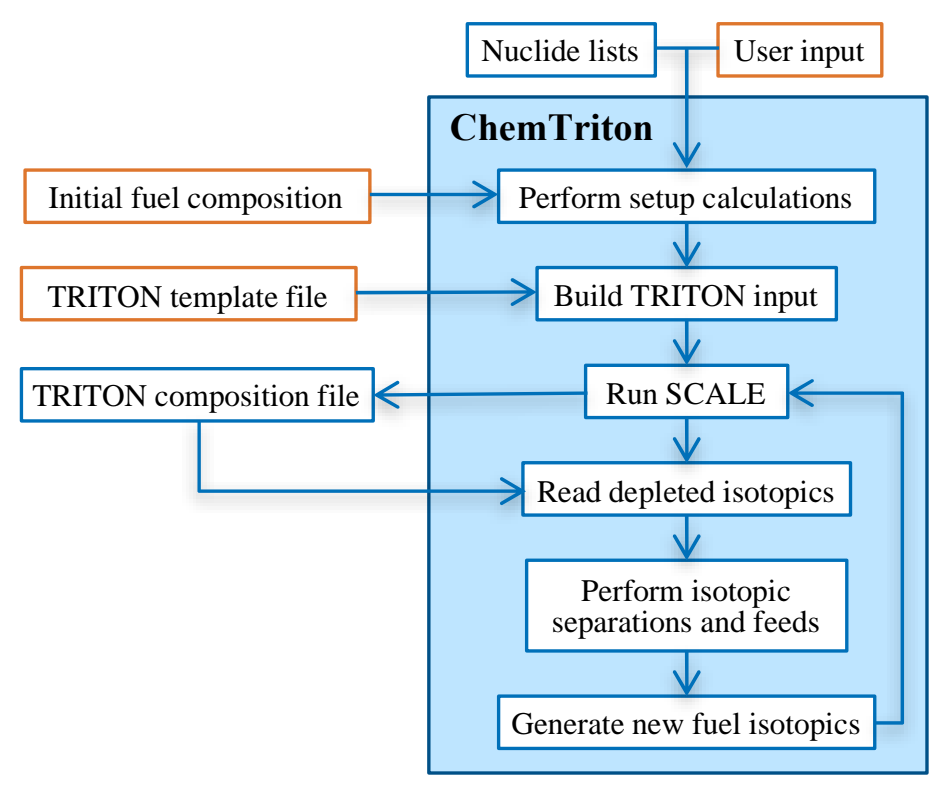

Figure 1. Flow chart for the ChemTriton modeling and simulation tool.

The primary function of ChemTriton is to manage chemical mixtures; SCALE performs most of the computationally intensive functions (e.g., neutron transport and depletion). With this primary function, it is natural to use the object-oriented approach and treat a material stream as an object. Each material stream represents a fluid in the core design and has specific characteristics (e.g., volume, isotopic composition, temperature, heavy metal mass, etc.). Additionally, there is a set of available actions for each stream (e.g., read and write stream isotopic information, separate out specific isotopes from stream, feed in specific isotopes to stream, combine and split streams). These 
attributes and actions encompass all the tools necessary to simulate the operation of a complex, multi-fluid, multi-zone MSR and are generic enough to apply to different types of systems (Betzler et al., 2016).

\subsubsection{Generic multi-fuel and multi-zone geometry capabilities}

To perform a depletion step, ChemTriton reads a user-defined external SCALE/TRITON template input file, builds the step $i$ input file, and runs SCALE/TRITON. After the calculation completes, ChemTriton reads the burned fuel composition files. ChemTriton only knows the volume and isotopic composition of a given mixture (fuel stream) within the template file; it lacks a specific knowledge of the geometry described by the SCALE/TRITON template input file. This provides ChemTriton with the flexibility and ease to model any geometry: e.g., an infinite medium, a unit cell, or a full fuel assembly. While in some applications the simple unit cell is sufficient to obtain an accurate spectrum within the fuel for depletion calculations with reduced calculation time, this flexibility provides high-fidelity geometry capabilities for comparisons to more rigorous models.

ChemTriton has the capability to manage as many fuel streams as desired. A given SCALE/TRITON template input file may have multiple depletion materials. At the end of a depletion step, ChemTriton reads the separate depleted compositions and tracks each fuel stream separately. Then, fuel streams are combined or split and undergo chemical separations. A potential application for this capability is a two-fluid fast MSR design with a coolant salt flowing in channels through a fuel salt (Fig. 2). In this application, ChemTriton separates fissile material bred in the coolant salt and feeds it to the fuel salt, continuously topping off the coolant salt with fertile 
material. There are additional applications for this capability, such as (1) including one or more waste material streams to account for materials being separated from the fuel salt, (2) defining streams for alternate (non-fuel) materials to study activation or radioactive isotope generation, and (3) including fuel streams for material that spends time outside the core.

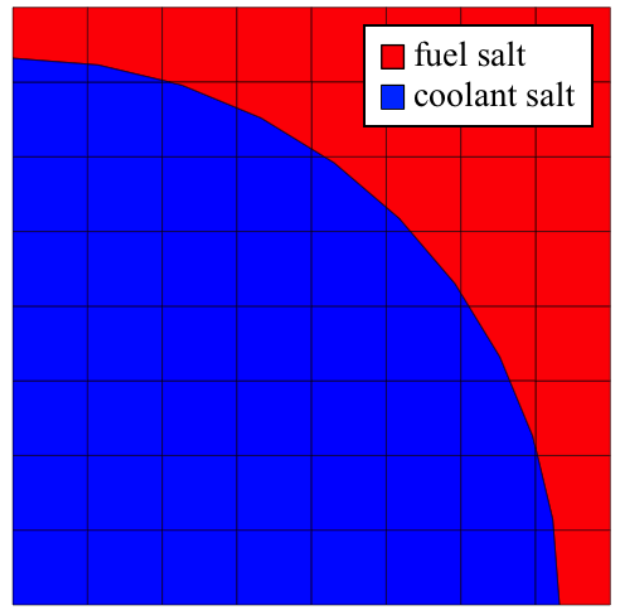

Figure 2. A multiple-fluid fast MSR unit cell model.

In addition to multiple fuel streams, ChemTriton is also able to use as many external SCALE/TRITON input files as desired. ChemTriton builds a step $i$ input file for each user-defined external SCALE/TRITON template input file and reads the burned fuel composition files only after all calculations (run simultaneously) are complete. This capability allows ChemTriton to model multi-zone systems without modeling the entire core in a single input file, which is impractical due to the large computational time required by the iterative approach. For example, a multi-zone model of the two-zone single-fluid molten salt breeder reactor (MSBR) (Bettis and Robertson, 1970) would require two models with different moderator-to-fuel ratios and the same fuel salt composition at the beginning of each step. The relative power sharing between the zones and the relative volume fraction of each zone are important factors to accurately define in multi-zone models. The power 
sharing determines the flux magnitude in each zone, which determines the burnup and breeding rates of fissile materials. The relative volume fractions define the amount of materials that are fed between the two zones. A whole-core single-state point model is recommended to determine the power sharing to be communicated to the ChemTriton multi-zone model. A limitation with this approach is that the power sharing is unable to communicate the shape of the flux spectrum; the calculated flux spectra in the various zones of the whole-core model will be different than the calculated flux spectra in the separate individual zone models. For cores with large variations in spectra (e.g., those with thermal and fast zones), adding zones to the multi-zone models more accurately describes the core spectrum, reducing the effect from these spectral differences. For thermal systems like the MSBR (with moderated and low-moderated zones), simple two-zone models have been shown to sufficiently capture the core depletion (Jeong et al., 2016). Note that for a whole-core ChemTriton model, the appropriate power sharing and flux spectrum are already determined by the SCALE/TRITON calculation.

\subsubsection{Time-dependent removal and feed rates}

Liquid-fueled MSR design largely focuses on the state of the reactor at an equilibrium condition, after fission products have built up in the fuel salt over years of operation (i.e., at high burnup). Though the isotopic makeup of the fuel salt continues to undergo small changes even after decades of operation, the major isotopes that contribute largely to the neutronic behavior of the MSR tend to reach an equilibrium concentration (i.e., vary only a fraction of a percent over several years). From the startup of an MSR until an equilibrium condition, the isotopic composition of the fuel salt undergoes significant changes (e.g., fission product, actinide, and fissile concentrations). 
During this time, the material feeds and separations should be optimized such that the MSR quickly transitions to an equilibrium state, where the material feeds and separations are more constant in time. A faster transition simplifies the operation of the reactor; in an equilibrium state, the fissile and fertile feed rates, safety metrics, and fission product mass removal rates are more constant in time.

ChemTriton is able to define time-dependent material feed and removal rates to study the effect of different elemental separations and/or feeds. The time dependence of the removals or feeds is defined with piecewise functions and may be dependent on certain conditions being met (e.g., concentration of fissile material below a specified limit). ChemTriton allows several options to define the units of the isotopic or elemental removals or feeds: mass feed or removal in $\mathrm{kg}$, makeup feed or removal to meet a desired concentration in atoms/b-cm, fractional removal or feed, or feeding mass from another stream. These capabilities allow ChemTriton to explore the effect of lower concentrations of fissile and fertile materials at reactor startup.

\subsubsection{Isotopic critical search functions}

In order for liquid-fueled systems to operate without excess reactivity, fissile material must be continuously fed to or generated in the core. For a system with breeding, the amount of fertile material affects both the breeding rate of fissile material and core criticality. While ChemTriton allows time-dependent fissile and fertile material feeds, defining these effectively at the beginning of the calculation requires some prior knowledge about the problem and ultimately lacks the efficiency of an on-the-fly concentration search. 
The ChemTriton critical concentration search runs SCALE iteratively, adaptively changing the concentration of a single selected isotope or element until satisfying a specified critical condition. This capability provides for a way to predict time-dependent fuel and/or fertile material feeds during startup to inform on MSR operations for those designs that do not operate with excess reactivity. This is similar to control poison density searches previously implemented in fuel cycle analysis tools (Toppel, 1983). ChemTriton stores the worth of the material to improve the initial guess for the next step and to reduce the number of iterations for each step. The search requires a user-defined external SCALE template file to perform the search. This template file may be the same as the SCALE/TRITON file used for ChemTriton depletion calculations, but this unnecessarily lengthens the computational time of the search. The user may choose to build a low-fidelity model of the geometry in any SCALE module (e.g., with a coarser transport mesh, few-group library, 1D geometry) to reduce the time spent in the critical search. These capabilities allow ChemTriton to study, for example, the feasibility of using variable thorium loadings in the MSBR, as applied below.

\section{Applications to Molten Salt Reactor and Fuel Cycle Modeling and Simulation}

The ChemTriton modeling and simulation tool is demonstrated in three applications: (1)

analyzing a transition to a thorium fuel cycle with MSRs, (2) studying the effect of fission product removal on core performance, and (3) the simulation of the equilibrium condition of a two-stage fuel cycle with solid-fueled reactors. The first two applications demonstrate MSR ChemTriton modeling, while the third uses ChemTriton to analyze a solid-fueled reactor fuel cycle. The third application also provides for a comparison of ChemTriton results to previous studies conducted for 
the E\&S (Wigeland et al., 2014). All calculations are run with SCALE version 6.2 Beta4 with the 252 group ENDF VII.1 cross-section library (Rearden and Jessee, 2016).

\subsection{Transition to a thorium fuel cycle with molten salt reactors}

With continuous fuel recycling, MSRs are an attractive implementation option for the reactor stage in the thorium fuel cycle because the ${ }^{233} \mathrm{U}$ bred from ${ }^{232} \mathrm{Th}$ is almost immediately recycled back through the core. At equilibrium, the only online fuel feed required is fertile ${ }^{232}$ Th to ensure that there is sufficient ${ }^{233} \mathrm{U}$ being produced to sustain criticality in the MSR. But, these reactors present a unique challenge for the transition to a thorium fuel cycle because the initial fissile and fertile materials are often mixed into the same molten fuel salt; separating these isotopes from the fuel salt is a non-trivial process.

All of the commercial power reactors operating today in the United States are light-water reactors (LWRs) fueled with low-enriched uranium (LEU) that convert ${ }^{238} \mathrm{U}$ into fissile plutonium, which often produces the majority of the fission power toward the end of the fuel's lifetime. In this fuel cycle, the important fissile isotopes are ${ }^{235} \mathrm{U},{ }^{239} \mathrm{Pu}$, and ${ }^{241} \mathrm{Pu}$. In contrast, the thorium fuel cycle is dependent on the conversion of the fertile isotope ${ }^{232} \mathrm{Th}$ to the fissile isotope ${ }^{233} \mathrm{U}$, an isotope that is not found in nature. This leads to a significant engineering challenge: without sufficient quantities of man-made ${ }^{233} \mathrm{U}$ (for use in the initial core so that it is able to sustain a chain reaction), the initial fissile material for the first reactors built using a thorium fuel cycle is not the fissile isotope being generated $\left({ }^{233} \mathrm{U}\right)$. The use of another initial fissile material (e.g., LEU) must be explored, modeled, and analyzed. Transitioning to a thorium fuel cycle is dependent on this

alternate fissile material until there is enough surplus ${ }^{233} \mathrm{U}$ to start up additional reactors. 
This analysis uses unit cell representations of an MSR design based on the ORNL MSBR, which is a graphite-moderated thermal-spectrum reactor design that converts ${ }^{232} \mathrm{Th}$ to ${ }^{233} \mathrm{U}$ with a breeding ratio of 1.06 at equilibrium. This section discusses the simulation of the startup of a thorium-based MSR with different initial fissile materials to identify challenges and limitations for deployment of this reactor technology.

\subsubsection{Model description and initial fissile materials}

Each unit cell of the two-region MSBR contains a cylindrical fuel salt flow channel within a graphite block, with additional fuel salt flowing through the interstitial gap between neighboring graphite blocks. The MSR model used in this work retains the use of a single fuel salt, but it differs from the MSBR design by using a one-zone approach in which the SCALE/TRITON model used for this study (Fig. 3) is a two-dimensional (2D) model with a fuel-to-moderator ratio that is the volumetric average of the two MSBR core regions (Robertson et al., 1971). Using a single average unit cell model reduces calculation time and simplifies the simulation. Breeding ratios would be enhanced if switched to a two-zone model. The 5-by-5 transport mesh for this simple unit cell model is optimized for delivering sufficiently accurate eigenvalue and spectrum information in a reasonable amount of time for fuel cycle analysis (Powers et al., 2013). 


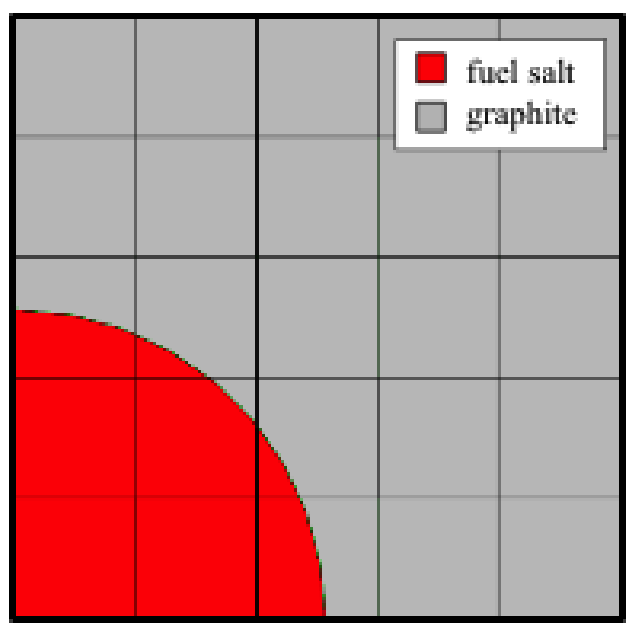

Figure 3. 2D MSR unit cell model showing the fuel salt channel (red) and graphite moderator (gray) (Powers et al., 2014).

The fuel salt is a mixture of $\mathrm{LiF}, \mathrm{BeF}_{2}, \mathrm{ThF}_{4}$, and $(\mathrm{HM}) \mathrm{F}_{N}\left(\mathrm{e}\right.$.g., $\mathrm{UF}_{4}$ or $\mathrm{PuF}_{3}$ ), where $\mathrm{HM}$ is the chosen initial fissile material, and $N$ is dependent on this fissile material and the thermochemical state of the fuel salt. The total thermal power of the reactor is 2,250 MWt, and each SCALE/TRITON depletion time step is three days. Previous parametric studies indicate that this time step length is sufficiently short enough to model the online removal of protactinium (i.e., on short enough time scales to achieve good conversion of ${ }^{232}$ Th to ${ }^{233} \mathrm{U}$ ) (Powers et al., 2013). Removal rates are specified using an element-specific cycle time, defined as the amount of time it takes to completely remove an element from the salt. After the three-day depletion calculation, some isotopes (e.g., noble metals and gaseous fission products) are separated from the fuel salt, and the protactinium is decayed to fissile uranium and recycled into the fuel salt. Accumulation of xenon gas during the short depletion calculation only slightly affects the spectrum used to collapse cross sections to obtain depleted isotopic compositions. While the semi-continuous batch removal treatment is unable to exactly simulate a true continuous removal process, the use of time steps 
shorter than three days offers little to no benefit in the accuracy of calculated eigenvalue and fuel cycle metrics (Powers et al., 2013).

This study examines the use of three different materials to provide the initial fissile loading for starting up an MSR (Fig. 4): ${ }^{233} \mathrm{U}$, LEU, and plutonium recycled from LWR spent nuclear fuel (LWR Pu). The isotope ${ }^{233} \mathrm{U}$ is included in the evaluation because it is the ideal fissile material to start up a thorium-based MSR (the salt composition with this initial fissile material is closest to the equilibrium fuel composition), and it can be produced within existing LWRs or other reactors before starting up an MSR or within another thorium-based MSR. The latter case is the methodology for starting up new MSRs in a post-transition thorium fuel cycle (i.e., MSRs breed surplus ${ }^{233} \mathrm{U}$ for starting up additional MSRs).



\footnotetext{
Note: Only primary material flows are shown. Material flows from imperfect separations (losses), low-level waste, and other secondary streams that will be produced in performing various fuel cycle functions are not shown.

Legend:

$\mathrm{U} 3=\mathrm{U}$ produced by $\mathrm{Th}$ fuel

LEU $=$ Low-enriched Uranium

FP = Fission Products

TRU $=$ Transuranics

$\mathrm{UF}_{4}=$ Uranium Tetrafluoride

$\mathrm{PuF}_{3}=$ Plutonium Trifluoride

$\triangle$ = Nuclear Waste Disposal

$\mathrm{ThF}_{4}=$ Thorium Tetrafluoride

MSR $=$ Molten Salt Reactor $/ \quad=$ Co-separated products

= Nuclear Material Storage

$>$ = Nuclear Material Transport
} 
Figure 4. The material flow diagram for the single-stage MSR fuel cycle showing a third fuel stream (FT-1.3) that represents the fissile material load at startup (Wigeland et al., 2014).

Both LEU and LWR Pu are part of the current commercial fuel cycles operating internationally today. To avoid the use of highly attractive special nuclear material, the uranium enrichment is restricted to LEU defined as less than $20 \%{ }^{235}$ U (IAEA, 2001). Two enrichments of LEU (4.8\% and $19.79 \%$ ) are included in the evaluation. Spent nuclear fuel (SNF) is an abundant source of LWR Pu (requiring separations via reprocessing prior to re-use) in which approximately $65 \%$ of the plutonium isotopes are fissile. An additional advantage of using plutonium as a startup fissile material is that it is a different element from the ${ }^{233} \mathrm{U}$ that is being bred; this simplifies separations because the plutonium is chemically separable from the uranium in the fuel salt. Blended ${ }^{238} \mathrm{U}-\mathrm{Pu}$ and ${ }^{238} \mathrm{U}-{ }^{233} \mathrm{U}$ are excluded from this study because the addition of ${ }^{238} \mathrm{U}$ reduces the feasibility of those sources of fissile material. Highly enriched uranium (HEU) is excluded from this study due to the unavailability of this material for use as an initial reactor fuel (due to proliferation risk concerns) (IAEA, 2001) and because the performance of this material is expected to be similar to ${ }^{233} \mathrm{U}$.

\subsubsection{Simplifying assumptions}

The purpose of this study is to identify the effects of using different initial fissile materials on the transition to, and equilibrium performance of, a thorium fuel cycle using MSRs. To highlight these effects and simplify the analyses, several assumptions are made.

In the first part of this study, the initial thorium loading, $m_{0} \mathrm{~kg}$, is the same regardless of the fissile material, and the thorium loading during operation, $m_{\mathrm{Th}}(t)$, was held constant 
(i.e., $m_{\mathrm{Th}}(t)=m_{0}$ ) with a variable feed rate (in $\mathrm{kg} / \mathrm{day}$ ) of fresh thorium. As thorium is a fertile material that absorbs neutrons, this has several large impacts on core neutronics, including negatively impacting reactivity and skewing the fuel-to-moderator ratio such that it would harden the energy spectrum. While a reduction in the thorium loading decreases the amount of initial fissile material necessary to make the core critical, the breeding rate of ${ }^{233} \mathrm{U}$ must be sufficient to maintain a critical MSR. The latter part of this study focuses on analysis of these two competing effects.

The solubility of heavy metals is a known issue for MSRs, but it is ultimately dependent on the type of carrier salt. For this evaluation, solubility limits for uranium and plutonium were deprioritized within reason (i.e., the molar fractions of $\mathrm{UF}_{4}$ and $\mathrm{PuF}_{3}$ were high $-\mathrm{a}$ little over a percent — but held at values considered to be reasonable to first-order for this study). Also, it is assumed that addition or removal of soluble material (e.g., $\mathrm{UF}_{4}$ ) has a small impact on the fuel salt volume; this volume change is ignored for this analysis.

Because the transport model is a unit cell with reflecting boundary conditions, the SCALE/TRITON calculated eigenvalue is the infinite multiplication factor $\left(k_{\infty}\right)$. Because of this, a core configuration is deemed to be sufficiently critical if $k_{\infty}>1.02$. This $2 \%$ excess criticality provides some allowance for neutron leakage in a finite (full-core) system. Neutron leakage is dependent on reactor size, and typical large thermal reactors have a leakage of approximately $3 \%$ (Duderstadt and Hamilton, 1976). Leakage in a 1000 MWe MSBR is expected to be slightly less at $2.44 \%$ (Robertson, 1971). If the $k_{\infty}$ is between 1.00 and 1.02 , the configuration requires some additional minor optimizations to make the unit cell sufficiently critical but is still considered feasible. It should be noted that the actual percentage of leakage is dependent on the geometry and materials of the specific reactor design. 
For this study, equilibrium is defined as when the $k_{\infty}$ of the unit cell and the ${ }^{233} \mathrm{U}$ concentration in the fuel salt are both largely invariant in time (i.e., vary only a fraction of a percent over several years). Unless specifically noted otherwise, the fissile material was loaded into the core only at startup (i.e., there was no additional feed or removal of fissile material during reactor operation).

\subsubsection{The effect of initial fissile material choice}

The optimum startup concentration for ${ }^{233} \mathrm{U}$ (when it is the only fissile material loaded at startup) is $6.195 \times 10^{-5}$ atoms/b-cm. With this concentration, the unit cell model is initially sufficiently critical (Fig. 5), and the MSR is able to transition to equilibrium relatively quickly (within several years of operation). This concentration is slightly lower than the equilibrium concentration of ${ }^{233} \mathrm{U}$ because the fission products created during operation have a significant negative effect on reactivity. The use of ${ }^{233} \mathrm{U}$ as the initial fissile material provides the most ideal transition to equilibrium.

In the first simulations for this study, the LEU and LWR Pu initial fuel salt compositions have the same fissile isotope concentrations as the optimum ${ }^{233} \mathrm{U}$ initial concentration (i.e., the combined concentration of ${ }^{239} \mathrm{Pu}$ and ${ }^{241} \mathrm{Pu}$ in the LWR Pu fuel salt, the ${ }^{235} \mathrm{U}$ concentration in the LEU fuel salt, and the ${ }^{233} \mathrm{U}$ concentration in the pure ${ }^{233} \mathrm{U}$ fuel salt are all equal). With lower fractions of fissile isotopes in the startup material, more total feed material is required to reach the desired fissile isotope concentration, leading to large heavy metal loadings and very high molar fractions of $\mathrm{UF}_{4}$ for the LEU initial cores (Table 1).

Table 1. Molar composition for initial fuel salts (values in molar percent) 


\begin{tabular}{lrrrr}
\hline Molecule & ${ }^{233} \mathbf{U}$ & $\mathbf{4 . 8 \%}$ LEU & $\mathbf{1 9 . 8 \%}$ LEU & LWR Pu \\
\hline $\mathrm{LiF}$ & 71.80 & 69.10 & 71.23 & 71.73 \\
$\mathrm{BeF}_{2}$ & 16.01 & 15.40 & 15.88 & 15.99 \\
$\mathrm{ThF}_{4}$ & 11.99 & 11.54 & 11.90 & 11.98 \\
$\mathrm{UF}_{4} / \mathrm{PuF}_{3}$ & 0.20 & 3.96 & 1.00 & 0.30 \\
\hline
\end{tabular}

The addition of nonfissile actinides in the LEU and LWR Pu initial fuel salts has a large negative impact on the reactivity of the unit cell, resulting in a reduction of initial $k_{\infty}$ for all cases (Fig. 5). The greater the amount of nonfissile actinides added with the initial fissile material, the greater the reduction in the initial $k_{\infty}$. The addition of more nonfissile actinides also lengthens the time it takes for the $k_{\infty}$ of the unit cell to reach a theoretical equilibrium (none of these configurations is actually feasible, so this is a purely mathematical observation). For example, the $k_{\infty}$ of the unit cell with LEU (4.8\%) as the initial fissile material is still increasing after 20 years of operation. Because these fuel salt compositions result in initially subcritical unit cells, the fissile material concentrations in the LEU and LWR Pu initial fuel salts must be increased to overcome the absorption by the additional nonfissile actinides.

The initial fissile material loading was increased for the LEU and LWR Pu fuel salt compositions until the unit cell model was sufficiently critical $\left(k_{\infty}>1.02\right)$ at the initial time step. These compositions are referred to as LEU+ and LWR Pu+ fuel salt compositions. The MSR model with LEU composition and an enrichment of $4.8 \%$ was too subcritical to overcome by increasing the fissile material loading and was excluded from this exercise; the focus was shifted to making an LEU+ fuel salt composition with an enrichment of $19.79 \%$ a feasible option for starting up an MSR. With the additional fissile material in the new compositions, the total initial heavy metal loadings and molar fractions of $(\mathrm{HM}) \mathrm{F}_{N}$ increase (Table 2). 


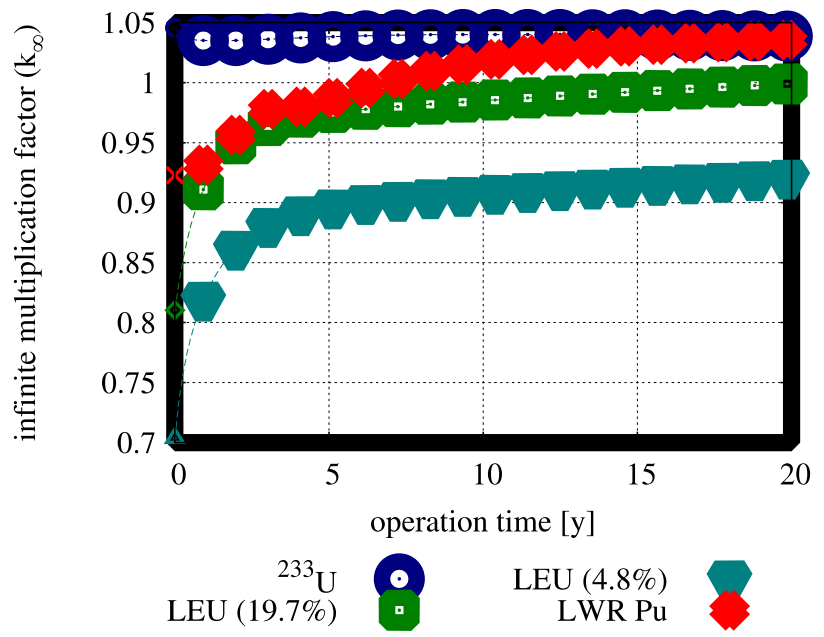

Figure 5. The calculated $k_{\infty}$ of the 2D pin cell for the initial fuel salts with identical initial fissile isotope concentrations.

Table 2. Molar composition for initial fuel salts (values in molar percent)

\begin{tabular}{lrr}
\hline Molecule & LEU+ & LWR Pu+ \\
\hline $\mathrm{LiF}$ & 70.19 & 70.66 \\
$\mathrm{BeF}_{2}$ & 15.65 & 15.75 \\
$\mathrm{ThF}_{4}$ & 11.72 & 11.80 \\
$\mathrm{UF}_{4} / \mathrm{PuF}_{3}$ & 2.44 & 1.79 \\
\hline
\end{tabular}

With the additional fissile material, the LEU+ and LWR Pu+ startup cores are initially sufficiently critical (Fig. 6), but as the initial fissile isotopes deplete and fission products are generated in the fuel salt, $k_{\infty}$ begins to decrease. For the LEU+ fuel salt, the equilibrium concentration of ${ }^{233} \mathrm{U}$ generated in the MSR after a few years (Fig. 7) is not sufficient to counteract the absorption of the ${ }^{238} \mathrm{U}$ added at startup. Eventually, enough of the original ${ }^{235} \mathrm{U}$ is depleted, and the core becomes subcritical within the first three years of operation before a near-equilibrium concentration of ${ }^{233} \mathrm{U}$ is reached. This illustrates that the moderator-to-fuel ratio of the unit cell is $24 / 57$ 
not ideal for the LEU+ and LWR Pu+ fuel salts; the moderator-to-fuel ratio is optimized for the equilibrium core, which contains ${ }^{233} \mathrm{U}$ and fertile thorium.

For the LWR Pu+ fuel salt, the ${ }^{233} \mathrm{U}$ concentration increases to nearly double that of the LEU+ fuel salt because the spectrum in the LWR Pu+ initial core is hardened; more ${ }^{232} \mathrm{Th}$ is being converted to ${ }^{233} \mathrm{U}$. Though this concentration is very high, it is still insufficient to counteract the neutron absorption in the nonfissile plutonium isotopes after much of the ${ }^{239} \mathrm{Pu}$ and ${ }^{241} \mathrm{Pu}$ is depleted. But, a decrease in the $k_{\infty}$ of the unit cell occurs at a much later operating time than for the unit cell with the LEU+ fuel salt composition.

After 6.7 years of irradiation, the LWR Pu+ fuel salt has less than $40 \%$ of its initial fissile plutonium, and $50 \%$ of the plutonium vector is composed of nonfissile isotopes (Fig. 8). Within a few more years, the plutonium in the fuel salt is absorbing more neutrons than it is creating via fission and contributes negatively to the reactivity of the unit cell.

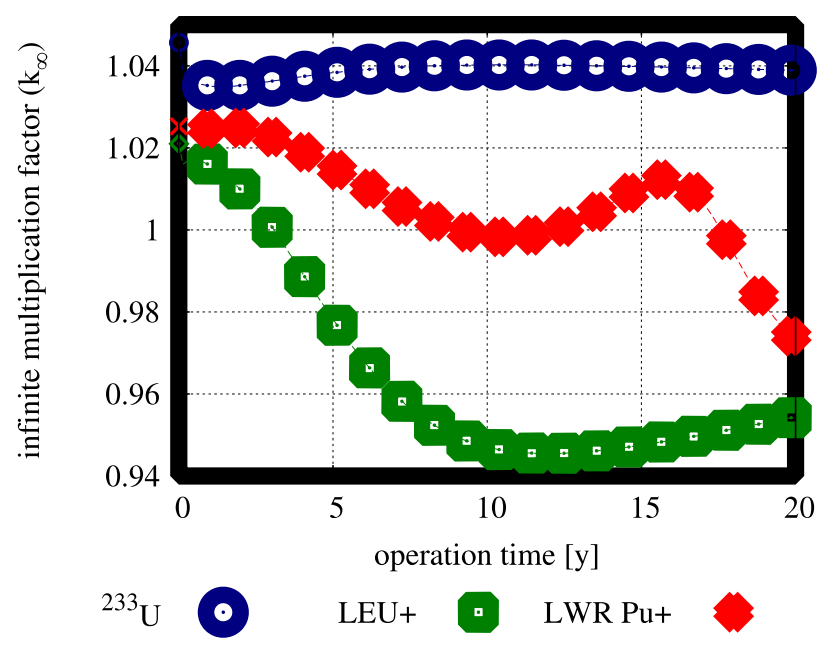

Figure 6 . The calculated $k_{\infty}$ of the 2D unit cell for the initial fuel salts with increased fissile material. 


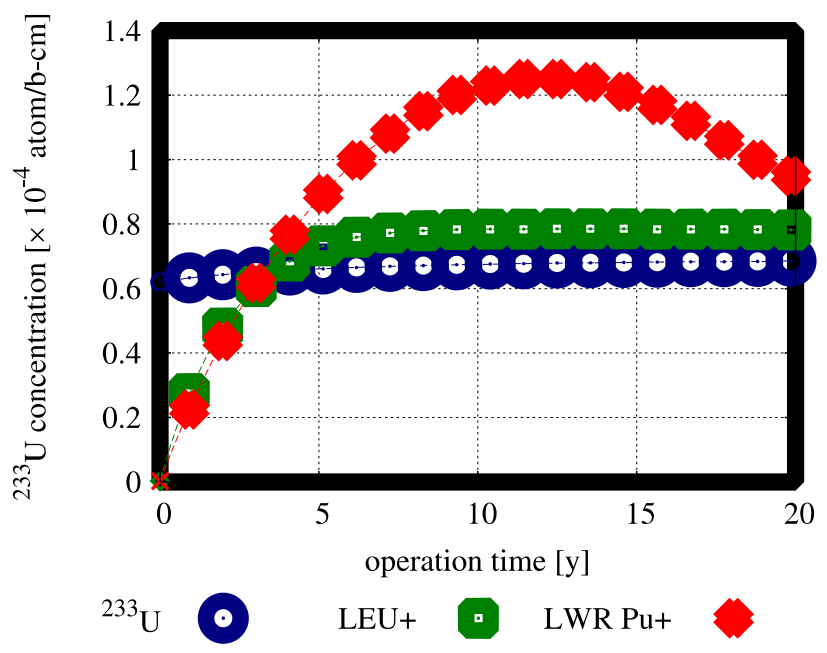

Figure 7. Simulated ${ }^{233} \mathrm{U}$ concentration for the initial fuel salts with increased fissile material.
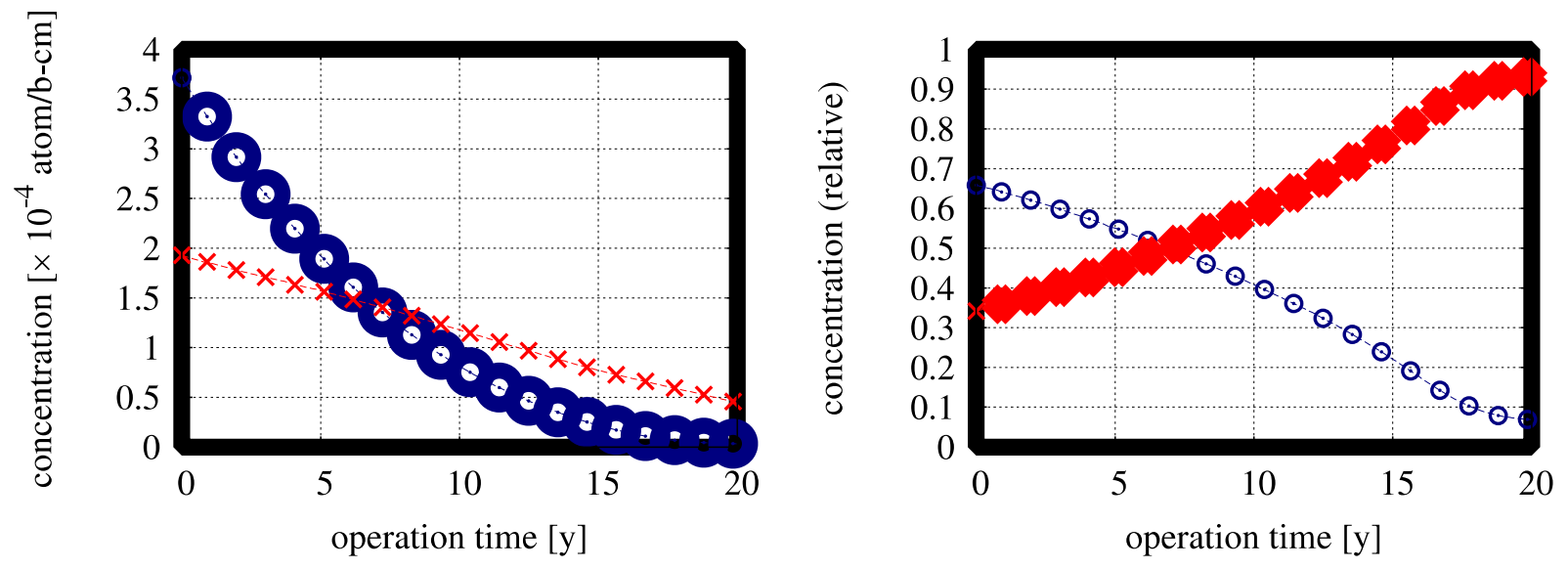

fissile

$\odot$ non-fissile

Figure 8. Absolute concentrations (left) and normalized vector (right) for fissile and fertile plutonium isotopes in the LWR Pu+ fuel salt.

After nearly 16 years of operation, the reactivity of the LWR Pu+ fuel salt begins to degrade very quickly (Fig. 6). This is caused by a relatively rapid spectral shift (Fig. 9). After much of the 
plutonium is burned and ${ }^{233} \mathrm{U}$ becomes the primary fissile isotope, the spectrum softens and approaches a thermal spectrum similar to that of the MSR in an equilibrium state (after years of operation with ${ }^{233} \mathrm{U}$ as the initial fissile material). This spectral shift severely impacts reactivity because the remaining plutonium (of which more than $80 \%$ is nonfissile) in the fuel salt becomes a more impactful absorber as the spectrum thermalizes.

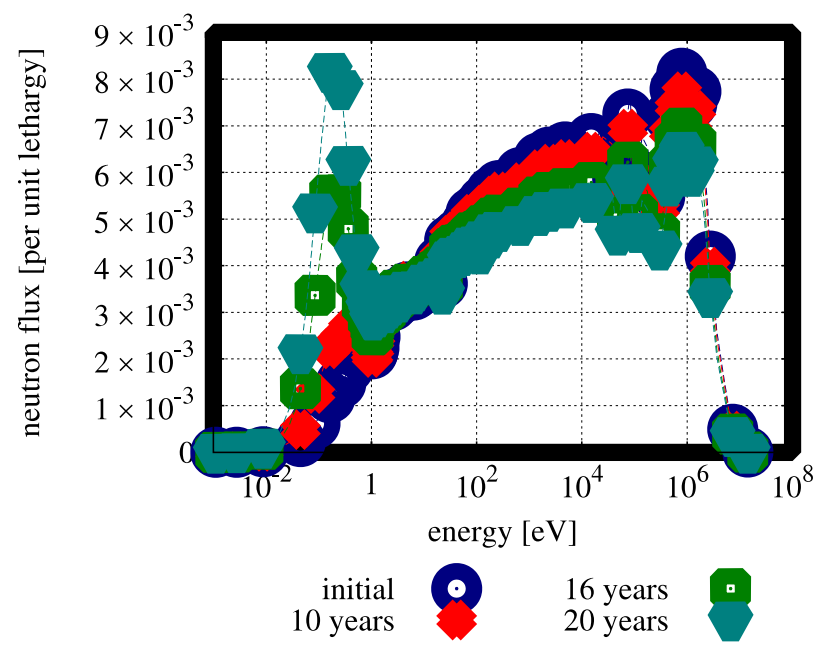

Figure 9. The spectrum in the LWR Pu+ fuel salt at different operating times.

\subsubsection{Actions that increase feasibility of initial fuel salt compositions}

One possible way to avoid the decreasing $k_{\infty}$ for the LWR Pu+ salt composition is to remove the plutonium from the fuel salt after it is no longer positively contributing to the unit cell reactivity. This option is viable because, chemically, $\mathrm{PuF}_{3}$ behaves differently than $\mathrm{UF}_{4}$ in the fuel salt, and the fissile isotope ${ }^{233} \mathrm{U}$ is not separated from the core in the process. This option is less attractive for the LEU-based fuel salts because in order to remove the absorptive ${ }^{238} \mathrm{U}$ isotope, the uranium must be separated by isotope in addition to being extracted from the fuel salt. 
After 7.8 years of operation, removing the entire inventory of plutonium causes an increase in unit cell reactivity. This timeframe was selected to perform a plutonium removal rate study, and ChemTriton was restarted to simulate the plutonium removal cases (Fig. 10). The selected cycle times (ct) of the three removal rates were 3 and 500 days (i.e., remove all plutonium every 3 or 500 days, respectively). An additional removal case is included in which plutonium removal began (with a cycle time of 3 days) during the spectral shift after 16 years of operation.

In all cases, the unit cell $k_{\infty}$ eventually increases to far above equilibrium before decreasing and slowly approaching the equilibrium $k_{\infty}$. This initial increase is caused by the high concentration of ${ }^{233} \mathrm{U}$ built up in the salt due to the hardened neutron spectrum. In the cases where the plutonium is removed at slower rates, the $k_{\infty}$ initially decreases over a short time period due to the combination of a decrease of the fissile plutonium isotopes and a slowly shifting spectrum. If all the plutonium is removed with a three-day cycle time, the spectrum thermalizes nearly instantaneously. Eventually, the ${ }^{233} \mathrm{U}$ concentrations in these LWR Pu+ removal cases approach the equilibrium concentration (Fig. 11).

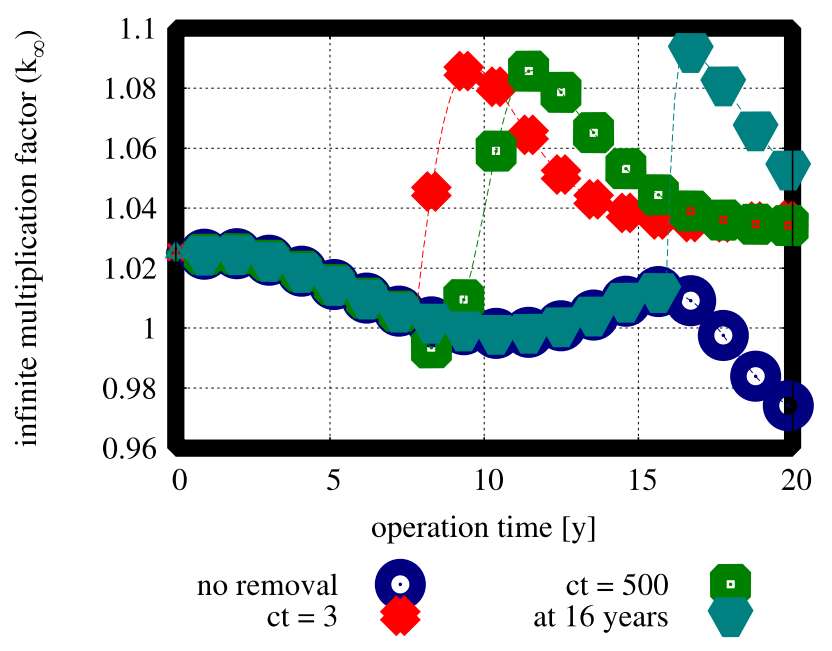


Figure 10. The calculated $k_{\infty}$ of the 2D pin cell for the LWR Pu+ fuel salt with plutonium removal.

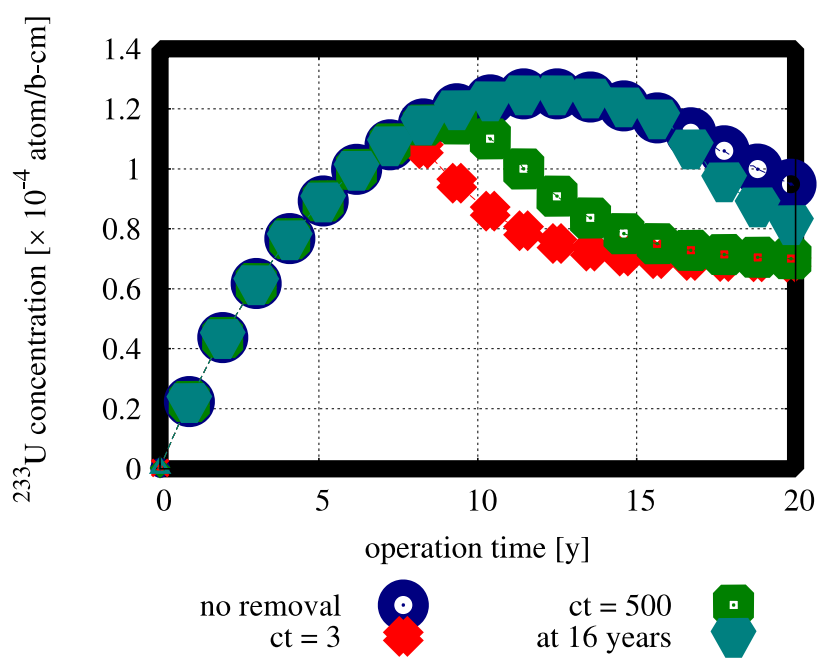

Figure 11. Simulated ${ }^{233} \mathrm{U}$ concentration for the LWR Pu+ fuel salt with plutonium removal.

A simulation with a variable thorium loading demonstrates the impact of the thorium concentration on $k_{\infty}$ (Fig. 12). The ChemTriton thorium search function adjusts the thorium loading until the calculated $k_{\infty}$ satisfies a specified condition. This function was applied to the LWR Pu+ case without removals. Though the unit cell is sufficiently critical throughout the simulation, the thorium concentration and the breeding rate of ${ }^{233} \mathrm{U}$ continually decrease. Due to decreased breeding rates, varying the thorium loading by itself does not make the LWR Pu+ fuel salt composition feasible, but combined with other actions, helps increase feasibility of these fuel salts. 




Figure 12. The calculated $k_{\infty}$ of the 2D unit cell for the LWR Pu+ fuel salt when the thorium loading is adjusted to maintain a specified criticality condition.

An alternative option for improving the feasibility of the LWR Pu+ fuel salt is to reduce the amount of heavy metals loaded into the core at startup, which requires a lower initial thorium loading. Reducing the initial thorium loading increases the initial $k_{\infty}$ (Fig. 13), allowing for a similar reduction in LWR Pu (Fig. 14). In these simulations, the total thorium loading during operation, $m$, is varied using a linear piecewise function where the ${ }^{232} \mathrm{Th}$ concentration increases linearly from $m_{0}$ in the first $T_{\mathrm{M}}$ years and is equal to $m_{\mathrm{Th}}$ thereafter:

$$
\begin{gathered}
m(t)=\frac{m_{\mathrm{Th}}-m_{0}}{T_{M}} t+m_{0} \text { for } t<T_{M} \\
m(t)=m_{\mathrm{Th}} \text { for } t \geq T_{M}
\end{gathered}
$$

In these first $T_{\mathrm{M}}$ years, the concentration increases from a chosen initial concentration of ${ }^{232} \mathrm{Th}\left(m_{0}\right.$ is reduced from $m_{\mathrm{Th}}$ by $0-50 \%$ in $10 \%$ increments). In addition to the time-dependent thorium loading, some simulations are started with a reduced initial plutonium loading. For these cases, the plutonium loading is reduced the same percentage as the thorium loading and no additional 
plutonium is added after startup. The LWR Pu+ initial fuel salt is used for these studies, but similar behavior is expected if LEU-based salts are used.

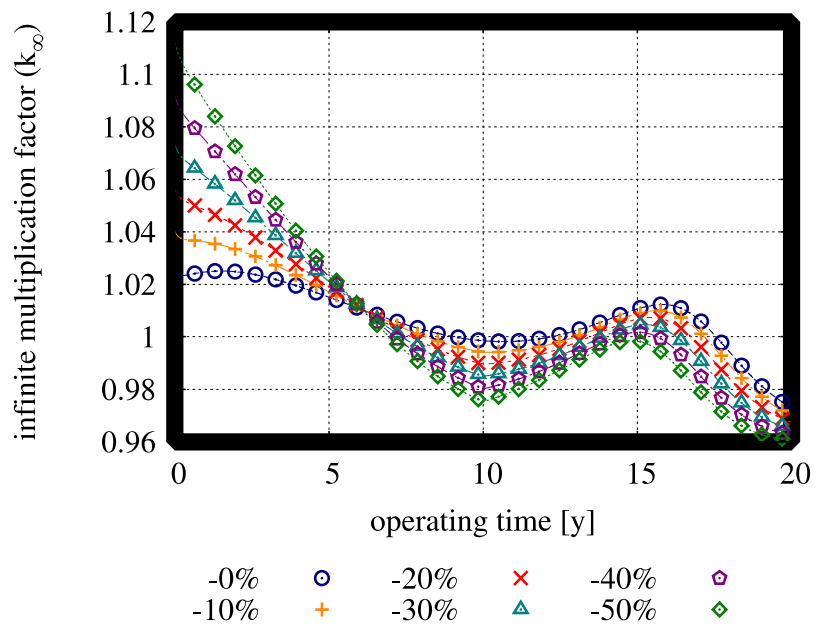

Figure 13. The calculated $k_{\infty}$ of the 2D unit cell with different reductions to the initial thorium loading $\left(T_{\mathrm{M}}=10\right.$ years $)$.



Figure 14. The calculated $k_{\infty}$ of the 2D unit cell with different reductions to the initial thorium loading and a matching reduction to the initial fissile plutonium loading ( $T_{\mathrm{M}}=10$ years $)$. 
Though the impact of the reduced breeding rate of ${ }^{233} \mathrm{U}$ from lower thorium loadings are not apparent in the first few years of operation, the effect is apparent after 10 years (Fig. 13). At this time, the case with the highest initial thorium loading has the highest $k_{\infty}$; this case has benefited from a higher ${ }^{233} \mathrm{U}$ breeding rate. An additional reduction to the initial plutonium loadings causes the initial fissile material to deplete earlier during operation (Fig. 14). Smaller amounts of initial fissile material deplete faster (the reactor power is the same in all simulations and is constant during operation). Even with these reduced loadings, many of the cases approach the $k_{\infty}$ of the unreduced calculation 5-9 years into operation before deviating significantly.

Reducing $T_{\mathrm{M}}$ reduces the reactivity penalty that results from a lower breeding rate of ${ }^{233} \mathrm{U}$ (Fig. 15). With a $T_{\mathrm{M}}$ of 2.5 years, the difference in $k_{\infty}$ after 10 years of operation is very small (on the order of a few hundred pcm). An additional reduction to the initial plutonium loading shows that it is possible to increase the $k_{\infty}$ at 10 years (Fig. 16). In these cases, the quicker recovery in the breeding rate combined with fewer nonfissile actinides in the fuel salt absorbing neutrons improves the outcome at 10 years. But, in some cases (e.g., the $50 \%$ reduction) this rapid increase in thorium quickly reduces $k_{\infty}$. These studies show that it is possible to reduce the thorium and initial plutonium loadings to obtain similar behavior with more thorium and plutonium. This action could simplify later separations of plutonium, or at least reduce the amount of plutonium that needs to be separated. 


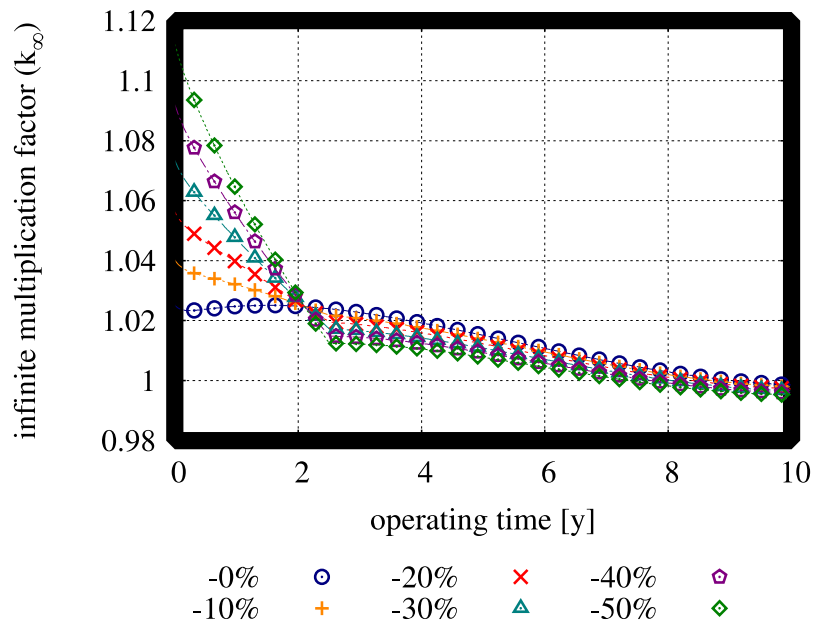

Figure 15. The calculated $k_{\infty}$ of the 2D unit cell with different reductions to the initial thorium loading $\left(T_{\mathrm{M}}=2.5\right.$ years $)$.

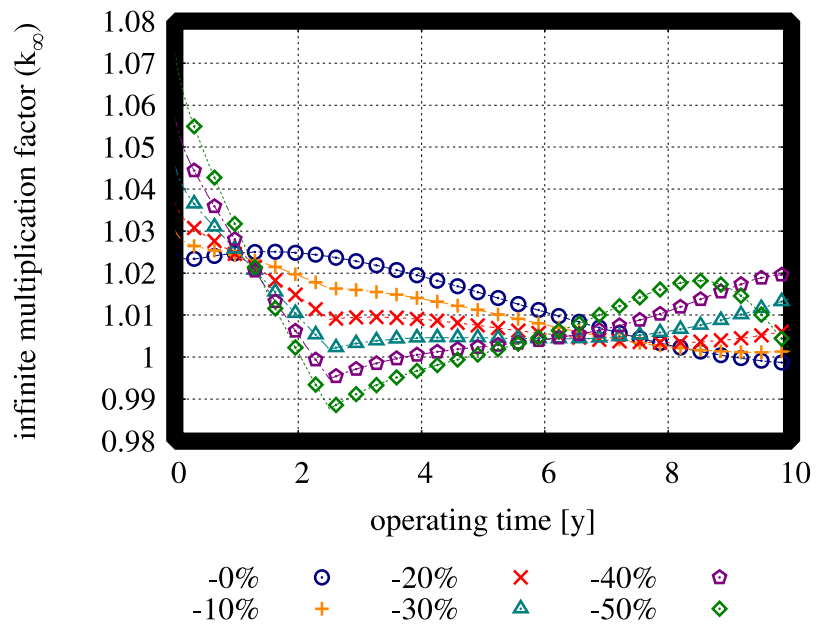

Figure 16. The calculated $k_{\infty}$ of the 2D unit cell with different reductions to the initial thorium loading and a matching reduction to the initial fissile plutonium loading $\left(T_{\mathrm{M}}=2.5\right.$ years $)$.

Though not intended to be an MSR design optimization study, this work demonstrates the importance of developing methods and tools to provide for such assessments, which are very 
important for MSR design work. Additionally, these studies show that the fuel cycle performance will be affected by assumptions, approaches, and optimization of key design and operation parameters (resources utilization, nuclear waste generation, etc.).

\subsection{The effect of fission product removal on fuel cycle performance}

In a solid-fueled reactor, fission products build up during reactor operation and negatively impact core reactivity. A potential benefit of a liquid-fueled reactor is that fission products that significantly affect core reactivity (i.e., those with a high concentration and large absorption cross section) may be separated during operation. This reduces the number of fissions necessary to maintain criticality, thereby reducing fuel consumption and increasing fuel utilization. To reduce radioactive material handling, some MSR designs only separate the fission products that are insoluble, physically plate out on cold surfaces (passive removal), or cause other salt chemistry or corrosion issues. Fewer MSRs are designed to perform additional separations (active removals) to increase reactor performance.

The previous work distinguished MSR salt treatments from processing (Gehin and Powers, 2016), classifying salt treatments as necessary due to chemistry issues and salt processing as reactor performance enhancements. This study placed elements into several processing groups: volatile gases (VG), noble metals (NM), seminoble metals, volatile fluorides, rare earth elements (REE), and discard (Table 3). Each element was assigned a characteristic cycle time, defined as the time required for the full removal of a given element. This study applies ChemTriton to quantify the neutronic benefit of the removal of each processing group. 
Table 3. Cycle times of elements removed from fuel salt (Gehin and Powers, 2016)

\begin{tabular}{llc}
\hline Processing Group & Elements & Cycle time \\
\hline Volatile gases & $\mathrm{Xe}, \mathrm{Kr}$ & $20 \mathrm{~s}$ \\
Noble metals & $\mathrm{Se}, \mathrm{Nb}, \mathrm{Mo}, \mathrm{Tc}, \mathrm{Ru}, \mathrm{Rh}, \mathrm{Pd}, \mathrm{Ag}$, & $20 \mathrm{~s}$ \\
& $\mathrm{Sb}, \mathrm{Te}$ & $200 \mathrm{~d}$ \\
Seminoble metals & $\mathrm{Zr}, \mathrm{Cd}, \mathrm{In}, \mathrm{Sn}$ & $60 \mathrm{~d}$ \\
Volatile fluorides & $\mathrm{Br}, \mathrm{I}$ & $50 \mathrm{~d}$ \\
& & $500 \mathrm{~d}$ \\
Rare earth elements & $\mathrm{Y}, \mathrm{La}, \mathrm{Ce}, \mathrm{Pr}, \mathrm{Nd}, \mathrm{Pm}, \mathrm{Sm}, \mathrm{Gd}$ & $3435 \mathrm{~d}$ \\
& $\mathrm{Eu}$ & \\
Discard & $\mathrm{Rb}, \mathrm{Sr}, \mathrm{Cs}, \mathrm{Ba}$ &
\end{tabular}

This analysis uses unit cell representations of an MSR design loosely based on the ORNL DMSR (Engel et al., 1980), which is a graphite-moderated thermal-spectrum reactor design. The unit cell uses the same fuel-to-moderator ratio as the DMSR, but it differs in size, power density, and fuel type. This section discusses the simulation of the fuel cycle of an LEU-based MSR with different fission product removals to identify benefits of the removal of different elements.

\subsubsection{Model description and fission product removals}

The unit cell model used in this study is derived from the 2D SCALE/TRITON model used in the previous study (Fig. 3), with the radius of fuel salt channel changed to reflect the fuel-to-moderator ratio of the DMSR (9.31\% fuel salt). The initial fuel salt contains $4 \%$ enriched LEU in a mixture of $\mathrm{LiF}, \mathrm{BeF}_{2}$, and $\mathrm{UF}_{4}$, in the molecular ratios outlined for the DMSR. The initial loading of the $\mathrm{UF}_{4}$ is assumed to be near maximum solubility in $\mathrm{FLiBe}\left(\mathrm{LiF}+\mathrm{BeF}_{2}\right)$ salt, and no additional feed material is provided during operation. Unlike the DMSR, the reactor represented by this unit cell model contains no thorium; this study is focused on examining the effect of fission 
product removals on a typical LEU fuel cycle. The total thermal power of the reactor is $400 \mathrm{MWt}$ (approximately $35.1 \mathrm{~W} / \mathrm{g}$ ) and each SCALE/TRITON depletion time step is three days. After the three-day depletion calculation, selected isotopes are separated from the fuel salt.

This study examines the use of different elemental removals during the operation of an LEU-based MSR. The effect of removing elements, both individually and combined, from each processing group (Table 3) is explored here. Both volatile gases and noble metals are included for all the combined cases because these are removed passively in most MSR designs; volatile gases will naturally separate from the fuel salt and noble metals will plate out on cold metal surfaces. While adjusting the cycle time will have an effect on the impact of the processing groups, the cycle times for all processing groups in this study are consistent. The initial composition of the fuel salt is the same, regardless of the selected fission product removals. Any effects from the skewed spectrum calculated during the SCALE/TRITON depletion calculations (for supercritical configurations) are ignored for this study.

\subsubsection{The effect of removing fission products from the core}

Loading this initial fuel salt composition into a unit cell model results in a supercritical configuration (Fig. 17). Following startup, the $k_{\infty}$ of the unit cell where volatile gases and noble metals were removed is approximately 5000 pcm higher than the case with no removals. This is due to the rapid removal ( $20 \mathrm{~s}$ cycle time) of these elements. The rare earth elements are removed at a more gradual rate (50 d cycle time); the effect of their removal is not evident until several months

after startup. The reactivity of this unit cell decreases over operation time as the fissile material ${ }^{235} \mathrm{U}$ continuously depletes out of the fuel salt and some fission products build up in the fuel salt. 
Eventually, this reactivity decreases to the point where the unit cell is subcritical; the remaining fissile ${ }^{235} \mathrm{U}$ and any bred fissile plutonium is not sufficient to overcome the absorption by the fission products and the ${ }^{238} \mathrm{U}$ remaining in the fuel salt. The time when the core reaches subcriticality $\left(k_{\infty}<1.02\right.$ for the unit cell) is taken as the core lifetime.

The core lifetime is well under three years without fission product removal (Table 4). While the removal of some processing groups does not significantly impact core lifetime, removal of volatile gases, noble metals, and rare earth elements each lengthen the core lifetime by $7-15 \%$. Combining the removals of these elements increases the cycle length by over $30 \%$. While there is significant neutronic benefit for removing elements in these three processing groups, other processing groups show less benefit due to lower absorption cross sections (e.g., volatile fluorides) or very large cycle times (e.g., discard processing group).

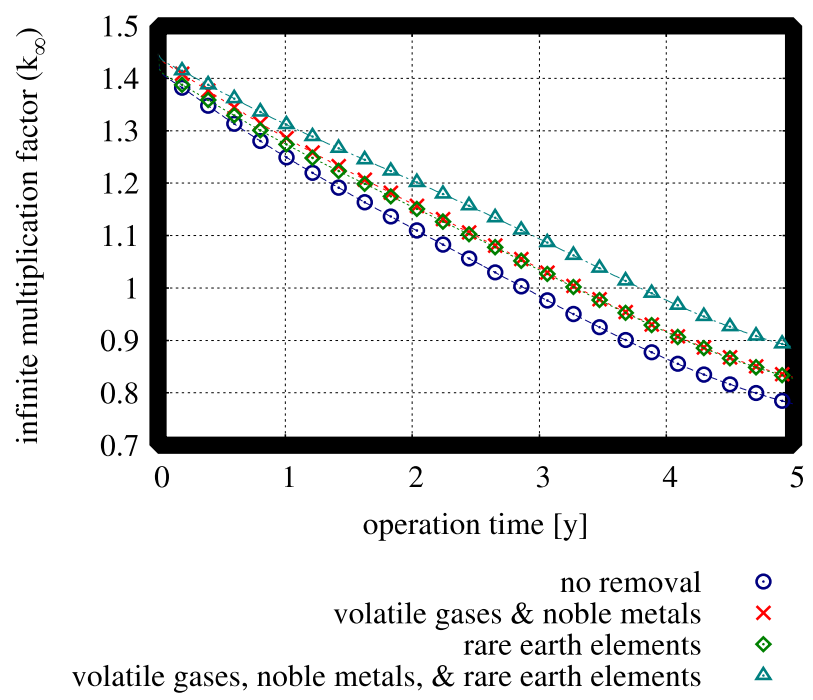

Figure 17. The calculated $k_{\infty}$ of the 2D LEU MSR unit cell with removal of different fission product groups.

Table 4. Effects on core lifetime with removal of different processing groups 


\begin{tabular}{lrr}
\hline \multicolumn{1}{c}{ Removals } & \multicolumn{2}{c}{ Core lifetime } \\
& time [y] & additional [+\%] \\
\hline None & 2.73 & - \\
Volatile gases & 2.93 & 7.5 \\
Noble metals & 2.92 & 7.1 \\
Seminoble metals & 2.74 & 0.3 \\
Volatile fluorides & 2.74 & 0.4 \\
Rare earth elements & 3.12 & 14.4 \\
Discard & 2.73 & 0.2 \\
Gases, noble metals & 3.14 & 15.1 \\
Gases, noble metals, seminoble metals & 3.14 & 15.2 \\
Gases, noble metals, fluorides & 3.14 & 15.2 \\
Gases, noble metals, rare earth elements & 3.63 & 32.9 \\
Gases, noble metals, discard & 3.14 & 15.1 \\
\hline
\end{tabular}

\subsection{Alternative application to a two-stage fuel cycle with an LWR}

In a two-stage fuel cycle, a given reactor (first stage) generates material that is fed into a different reactor type (second stage). One potential two-stage cycle involves a sodium-cooled fast reactor (SFR) feeding bred plutonium into a thermal mixed-oxide (MOX) LWR (Fig. 18). This fuel cycle does not need enriched uranium as an external feed material. At the end of irradiation, the spent MOX LWR fuel is cooled and reprocessed, and uranium and plutonium is separated and recycled to provide material to make more MOX LWR fuel (Sen and Youinou, 2013). An additional feed of SFR-recovered uranium and plutonium supplement the recycled MOX LWR fuel (Bays and Youinou, 2013). The isotopic content of this recycled fuel is dependent on several factors, including the uranium-to-plutonium ( $\mathrm{U}: \mathrm{Pu})$ ratio of the external feed, the SFR plutonium quality, the burnup of the MOX LWR fuel, and the initial content of the MOX LWR fuel. 


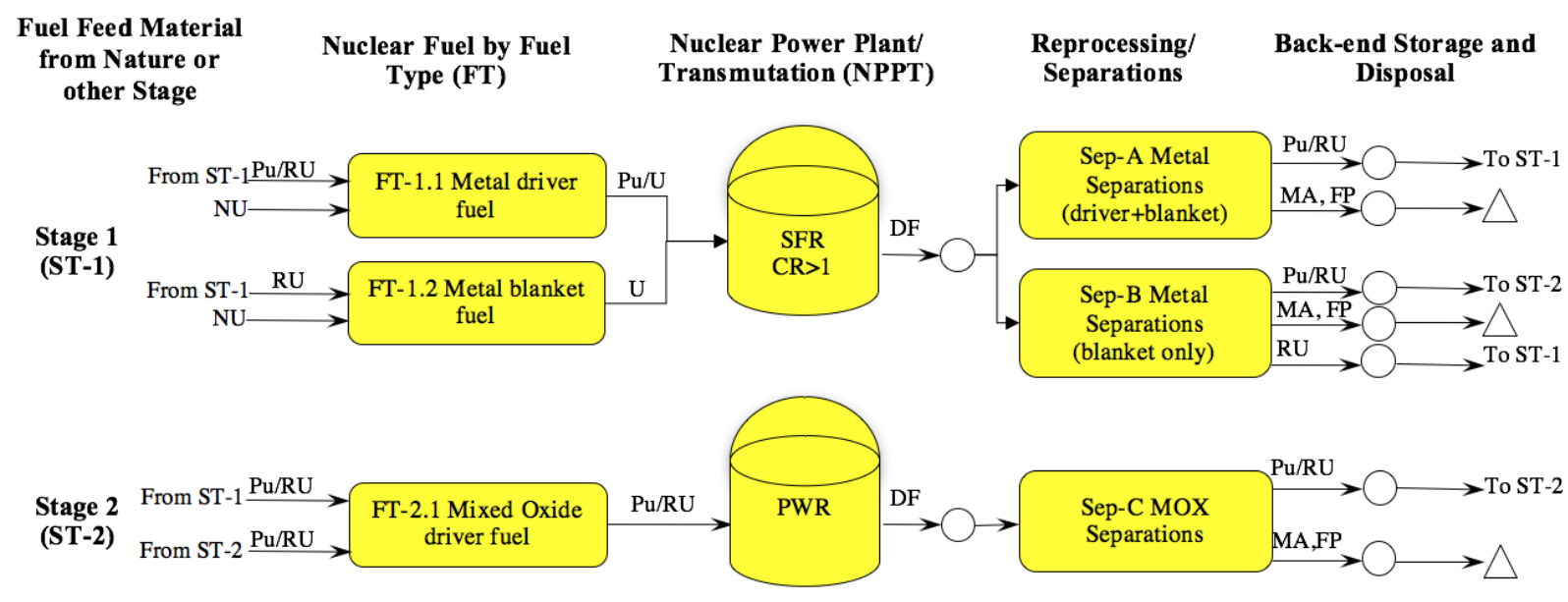

Note: Only primary material flows are shown. Material flows from imperfect separations (losses), low-level waste, and other secondary streams that will be produced in performing various fuel cycle functions are not shown.

Legend:

$\mathrm{RU}=$ Recovered Uranium $\quad \mathrm{DF}=$ Discharged Fuel $\quad$ PWR $=$ Pressurized Water Reactor $\quad=$ Nuclear Waste Disposal

MA = Minor Actinides $\quad$ FP $=$ Fission Products $\quad$ SFR = Sodium Fast Reactor $O=$ Nuclear Material Storage

MOX $=$ Mixed Oxide $\quad$ Pu/RU = Co-separated products $\longrightarrow=$ Nuclear Material Transport

Figure 18. The material flow diagram for the two-stage SFR-to-MOX LWR fuel cycle

(Wigeland et al., 2014).

This study uses ChemTriton to determine the equilibrium content of the MOX LWR fuel. Note that ChemTriton only models the MOX LWR and assumes a fixed feed of external material (plutonium vector and U:Pu ratio) from the SFR. Additionally, ChemTriton inherently tests the feasibility of the defined external material feed in terms of the eigenvalue, $k_{\infty}$ (e.g., verifies that the $\mathrm{U}: \mathrm{Pu}$ ratio has sufficient fissile material to continue MOX LWR operation). This study demonstrates the applicability of ChemTriton to a non-MSR related problem and provides for a comparison of results to previous studies completed for the E\&S (Wigeland et al., 2014). These studies used a similar problem definition with SCALE/TRITON but used different assembly models, initial conditions, and irradiation lengths (Sen and Youinou, 2013). These studies determined that the $k$ of the assembly continues to vary for the first 10 steps (109 years), and the 
equilibrium isotopic continue to vary for at least the first 15 steps (160 years) before converging to a fuel composition with a $\mathrm{Pu}$ content of $9.13 \%$ with $57 \%$ as ${ }^{239} \mathrm{Pu}$.

\subsubsection{Model description and two-stage parameters}

The unit cell model used in this study is derived from a 2D SCALE/TRITON model of a Westinghouse $17 \times 17$ fuel assembly. Note that the full assembly model could be used but would increase calculation time. The initial fuel composition is a typical MOX-type fuel with a 9.18\%

plutonium content (as a percentage of all heavy metals) and a ${ }^{239} \mathrm{Pu}$ content of $75 \%$ (as a percentage of plutonium mass). This SCALE/TRITON template file specifies a 1250-day full power (40 W/g) burn using five transport sub steps followed by a 3650-day cooling time. Thus, instead of small three-day depletion calculations, ChemTriton is configured to calculate the entire depletion of a solid-fueled assembly.

At the end of a depletion calculation, ChemTriton reads the burned and decayed fuel mixture and reprocesses the fuel, removing $1 \%$ of the uranium and plutonium to account for fabrication losses and $100 \%$ of all other elements. The remaining mixture is the uranium and plutonium that will fuel the next cycle. Additionally, an external feed made up of $60 \%$ SFR recovered uranium (Table 5) and $40 \%$ SFR plutonium (Table 6) is added to the fuel for the next cycle. The total mass of the external feed is equal to the mass of heavy metal that was burned and lost during fabrication from the previous depletion calculation (i.e., the total heavy metal mass is the same at the beginning of each depletion calculation). 
Table 5. Sodium fast reactor recovered uranium vector

\begin{tabular}{lr}
\hline Isotope & Weight \% \\
\hline${ }^{234} \mathrm{U}$ & 0.0001 \\
${ }^{235} \mathrm{U}$ & 0.1224 \\
${ }^{236} \mathrm{U}$ & 0.0185 \\
${ }^{238} \mathrm{U}$ & 99.859 \\
\hline
\end{tabular}

Table 6. Sodium fast reactor plutonium vector

\begin{tabular}{lr}
\hline Isotope & Weight \% \\
\hline${ }^{238} \mathrm{Pu}$ & 0.076 \\
${ }^{239} \mathrm{Pu}$ & 94.289 \\
${ }^{240} \mathrm{Pu}$ & 5.306 \\
${ }^{241} \mathrm{Pu}$ & 0.242 \\
${ }^{242} \mathrm{Pu}$ & 0.087 \\
\hline
\end{tabular}

\subsubsection{Simulation of equilibrium fuel composition}

After 8-10 depletion steps, the cycle-averaged calculated $k_{\infty}$ of the MOX LWR unit cell reaches a stable equilibrium well above 1.0 (Fig. 19). The cycle-averaged $k_{\infty}$ is obtained by averaging the calculated $k_{\infty}$ from each transport calculation during a given depletion calculation. With five depletion sub steps, SCALE/TRITON performs six transport calculations (Fig. 19). Factoring in the five-year cooling time, it takes well over 60 years to reach a stable equilibrium. These findings are consistent with the previous study (Sen and Youinou, 2013). This cooling time significantly delays the recycling of uranium and plutonium from the burned fuel; this is an illustration of how a liquid-fueled MSR benefits from immediate recycling of fuel material that a solid-fueled system lacks. 


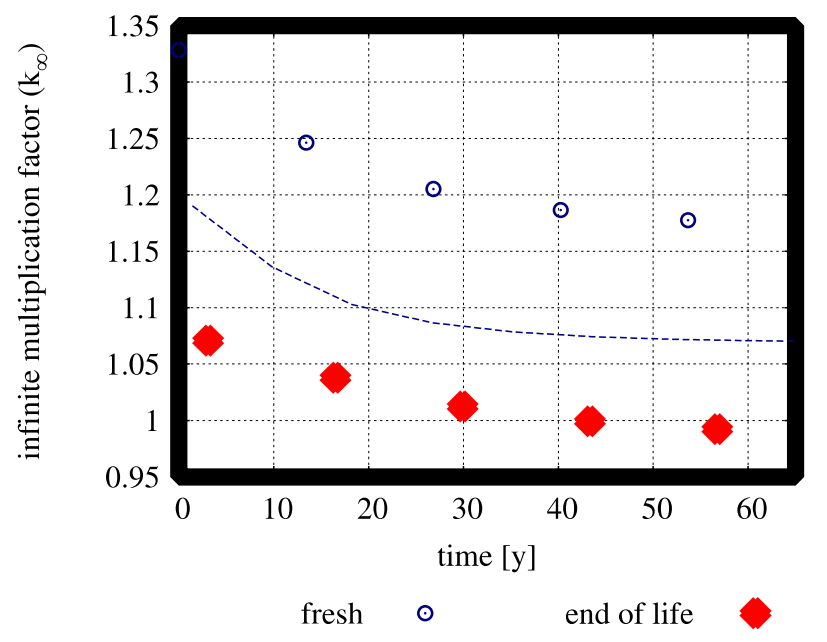

Figure 19. The calculated $k_{\infty}$ at the beginning (fresh) and end of life for the 2D MOX LWR assembly. The dashed line shows the cycle-averaged $k_{\infty}$.

ChemTriton converges on a stable fuel composition after approximately 20 depletion steps (Fig. 20). Factoring in the fuel cooling time, the fuel composition continues to change for the first 200 years. Though the calculated $k_{\infty}$ reaches an equilibrium in 8-10 steps, the fuel composition continues to undergo small isotopic changes for the next 10 steps. The difference between these calculated equilibrium times implies that the small isotopic changes after 60 years have little effect on the neutronic behavior of the unit cell. At equilibrium, plutonium content in the fuel is $9.60 \%$ and the isotopic ${ }^{239} \mathrm{Pu}$ content is $59.0 \%\left({ }^{241} \mathrm{Pu}\right.$ makes up the remaining $7.3 \%$ of the fissile plutonium). These findings are consistent with the trends found in the previous study (Sen and Youinou, 2013), which stopped calculating the isotopic concentrations after 15 depletion steps (i.e., the plutonium content and ${ }^{239} \mathrm{Pu}$ are both increasing at step 15 in the previous study). Restarting the ChemTriton calculation with this equilibrium concentration at the first depletion step (instead of the 
9.18\% plutonium content initial fuel as shown here) would greatly reduce the time for the fuel composition to reach equilibrium.
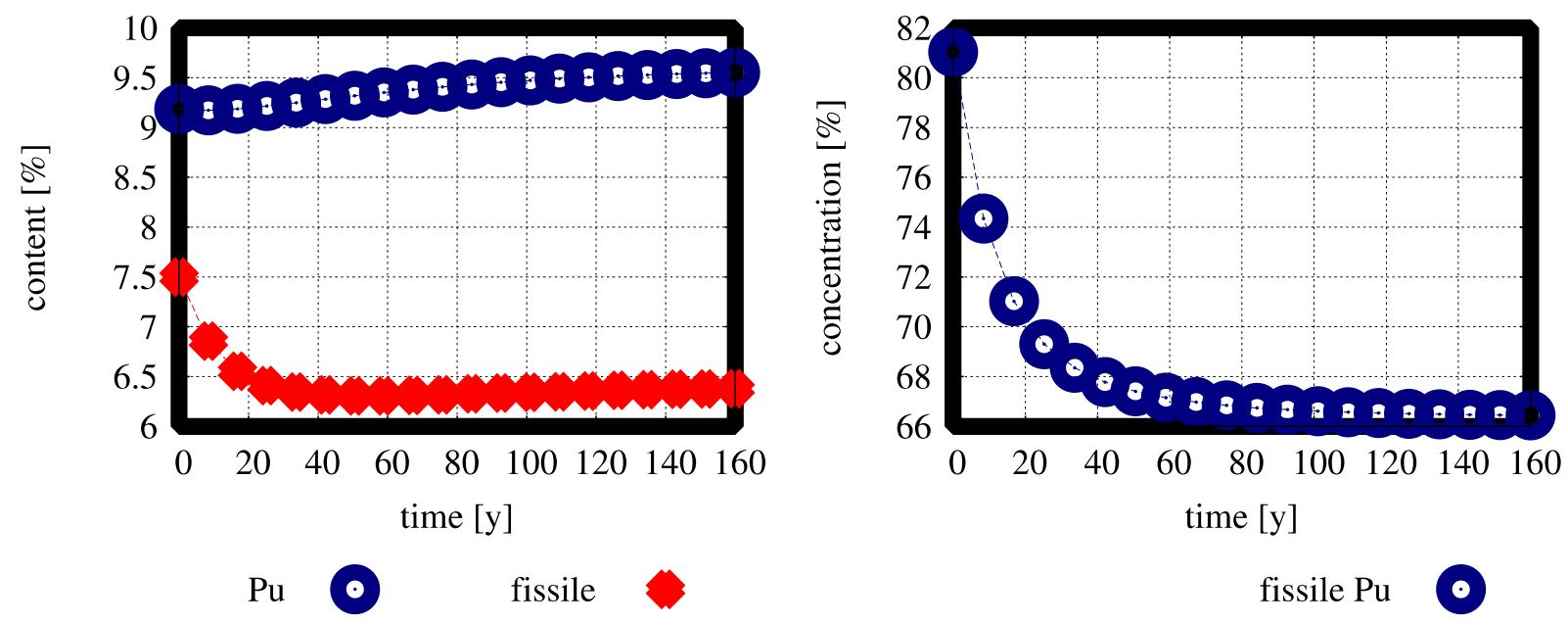

Figure 20. The plutonium and fissile material content in the fuel (left) and fissile plutonium content (right) in the MOX LWR fuel at the beginning of each depletion step (before burnup).

\section{Discussion and Conclusions}

The ChemTriton modeling and simulation tool expands the capability developed for simulating MSR operations (Powers et al., 2013), providing a generic tool for fuel cycle and liquid-fueled system problems. Advantages of ChemTriton include generic geometry modeling, multi-zone and multi-fluid capabilities, time-dependent feed and removal rates, and critical concentration searches. ChemTriton is demonstrated in three unique applications: simulating the startup of a thorium-based MSR using different initial fissile materials, the effect of fission product removal on MSR operation, and the simulation of the equilibrium composition of a MOX LWR fuel in a two-stage system. 


\subsection{Challenges for the transition to a thorium fuel cycle}

The modeling and simulation of the startup of a thorium-based MSR identified key challenges in transitioning to a thorium fuel cycle with a liquid-fueled MSR. Of the three materials evaluated $\left({ }^{233} \mathrm{U}\right.$, LEU, and LWR Pu), the most beneficial initial fissile material for starting up an MSR is ${ }^{233} \mathrm{U}$. However, the ${ }^{233} \mathrm{U}$ in this case is pure fissile material, so the comparison to LEU and LWR Pu is not entirely fair. Similar success is expected if better quality plutonium or HEU is used. Pure ${ }^{233} \mathrm{U}$ is selected (as opposed to a lower enrichment of ${ }^{233} \mathrm{U}$ ) because at equilibrium nearly all fissile material and uranium in the MSBR is ${ }^{233} \mathrm{U}$. Thus, the MSBR loaded with this fuel option is closer to equilibrium at core start up than any of the other cases examined (this is the best-case scenario).

Between the LEU+ and LWR Pu+ fuel salts, the latter is a more beneficial option for two main reasons: (1) It has a higher fissile material content than the LEU+ fuel salt, and (2) it is possible to chemically separate $\mathrm{PuF}_{3}$ from the fuel salt after it becomes a negative contributor to core reactivity. The LEU+ fuel salt core is less desirable because the large amount of ${ }^{238} \mathrm{U}$ loaded into the core at start up is difficult to remove (i.e., it requires both salt separation and isotopic separations).

If a significant amount of nonfissile actinides is loaded into the fuel salt, it must be removed at some later point during reactor operation. If these isotopes are left in the reactor, the MSR will not reach equilibrium within a reasonable amount of time. It is also possible to reduce the amount of nonfissile actinides loaded into the fuel salt by optimizing the thorium loading for the first few years of operation. For $\mathrm{LWR} \mathrm{Pu}$, it is conceivable that $\mathrm{PuF}_{3}$ can be separated from the fuel salt, but this waste must be accounted for. If LEU is the desired startup fissile material, then there is a significant 
engineering challenge in devising a way to separate the $\mathrm{UF}_{4}$ from the fuel salt, isotopically separate out ${ }^{238} \mathrm{U}$, and recycle the fissile uranium back to the fuel salt.

The ${ }^{233} \mathrm{U}$ fuel salt composition transitions to equilibrium quickly (in as few as ten years) because nonfissile actinides are not added to the fuel salt. The LWR Pu+ fuel salt composition reaches equilibrium in $\sim 20$ years if the plutonium is removed after 7.8 years of operation. These results indicate that MSRs are able to use plutonium from LWR SNF for startup.

Additional challenges are related to the spectrum of the core with certain fissile material loadings. The MSBR is designed to be a thermal reactor, but the spectrum hardens significantly when loaded with the LWR Pu+ fuel salt composition. This impacts core components, shielding, and safety. For example, structural components likely have a shorter lifetime, the graphite will undergo dimensional changes at a different rate, and the control rod worth may be different depending on the absorber type. The core components and safety shim must be designed to deal with a significant spectral shift. In some cases, a spectral shift would be beneficial as it may be used to increase the production of fissile material during the cycle and maximize the burnup of a specific fuel.

\subsection{Considerations for fission product removal in molten salt reactor design}

Removing specific elements from a molten fuel salt is a complex process that requires intelligent design (separations equipment design, fuel salt flow to equipment, etc.) and has a non-negligible economic cost. Furthermore, storing and handling waste consisting of highly concentrated radioactive material that includes a variety of metals and metalloids, as well as gases and other non-metals that may be stored in different forms, is an engineering challenge (in 
solid-fuel systems, these wastes are held up physically in fuel assemblies). But, leaving all fission products within the molten fuel salt is an invalid design approach because some elements are chemically incompatible with the molten fuel salt. For these reasons, some MSR designs include separations of the few elements that must be separated (e.g., using a cold trap to capture noble metals or sparging fission product gases). For some fission products, removal is a performance issue and the problem is economic; for a given element, the enhancement to core performance must outweigh the cost of removal. Removing all fission products is impractical; this would lead to an unstable system as some fission products are the delayed neutron precursors that allow a reactor to be controlled on the order of $\mathrm{s}^{-1}$.

The removal of noble metals, volatile gases, and rare earth elements from a fuel salt during operation has significant neutronic benefits. While it is not surprising that the immediate removal of fission product gases (e.g., xenon) and noble metals have a net positive effect on core lifetime (7\% each), the effect of removing smaller fractions of rare earth elements $\left(1 / 50^{\text {th }}\right.$ of the rare earth elements per day) has twice the impact on core lifetime (15\%). Removal of the rare earth elements is both a performance and salt chemistry issue; in molten fuel salt, the rare earth elements are trivalent and decrease plutonium solubility.

\subsection{Two-stage fuel cycle design}

To quantify the performance of a two-stage fuel cycle, the mass flow rates of materials between and to the two stages are analyzed at an equilibrium state. At equilibrium the material charged at step $i$ is the same as the material charged at step $i+1$, and the material discharged at step $i$ is the same as the material discharged at step $i+1$. This equilibrium depends on power sharing between the 
two reactors, the material passed between them, core physics (e.g., energy spectrum), discharged fuel burnup, and external feed materials. These variables define a complex problem, and different equilibria may be reached with different assumptions.

With a 3:2 ratio makeup feed of recovered uranium to SFR plutonium, a MOX LWR with a full recycle of uranium and plutonium fuel will reach a stable, feasible equilibrium fuel composition when starting from a MOX fuel composition found in current typical MOX assemblies. Due to the five-year cooling time of the spent MOX fuel, this equilibrium is reached only after 125 years, which contrasts liquid-fueled systems that are immediately able to recycle burned fuel material. Starting with an initial fuel composition that is closer to the equilibrium composition would greatly reduce the time to equilibrium.

\subsection{Future work}

The groundwork laid in previous efforts (Powers et al., 2013) and the continuing development in ChemTriton provides ongoing opportunities for application of this type of liquid-fueled system and fuel cycle analysis tool. ChemTriton would benefit greatly from several method enhancements such as using ORIGEN to calculate continuous removals and feeds instead of using a semi-continuous batch scheme to approximate this, implementing some chemical control modules to track chemical compounds that are formed in the molten fuel salt, incorporating solubility limits to control the amount of specific compounds dissolved in the fuel salt, and adding more intelligent reactivity control capabilities. Whether these features are incorporated into ChemTriton or built into the capabilities of another tool within SCALE remains to be seen. There are also several additional application projects and potential extensions to the analysis shown here, including design and 
optimization of MSRs, analysis of fast reactor designs, benchmarking multi-zone unit cell representations of cores to whole core models, benchmarking to other available tools, modeling both reactor types in a two-stage system, and expanding the fission product removal study to include more elements and cycle time parametric studies.

\section{Acknowledgments}

This work has been funded by the Fuel Cycles Options Campaign of the Fuel Cycle Technologies initiative of the US Department of Energy Office of Nuclear Energy. This manuscript has been authored by employees of Oak Ridge National Laboratory, managed by UT-Battelle LLC under US Department of Energy contract DE-AC05-00OR22725.

\section{References}

A. Ahmad, E. B. McClamrock, A. Glaser, "Neutronics calculations for denatured molten salt reactors: Assessing resource requirements and proliferation-risk attributes," Annals of Nuclear Energy, 75:261-267 (2015).

M. Aufiero, A. Cammi, C. Fiorina, and M.E. Ricotti, “An extended version of the SERPENT-2 code to investigate fuel burn-up and core material evolution of the Molten Salt Fast Reactor," Journal of Nuclear Materials, 441(1):473-486 (2013).

Aufiero, Manuele, et al. "Calculating the effective delayed neutron fraction in the molten salt fast reactor: analytical, deterministic and Monte Carlo approaches." Annals of Nuclear Energy, 65 (2014): 78-90. 
H. F. Bauman, G. W. Cunningham, III, J. L. Lucius, H. T. Kerr, C. W. Craven, Jr., "ROD: A Nuclear and Fuel-Cycle Analysis Code for Circulating-Fuel Reactors," ORNL-TM-3359, Oak Ridge National Laboratory (1971).

S. E. Bays and G. J. Youinou, Analysis of Pu-Only Partitioning Strategies in LMBFR Fuel Cycles, INL/EXT-13-28492, Idaho National Laboratory, February 2013.

E. S. Bettis and R. C. Robertson, "The Design and Performance Features of a Single Fluid Molten-Salt Breeder Reactor," Nuclear Applications and Technology, Volume 8, 190-207 (1970).

B. R. Betzler, J. J. Powers, and A. Worrall, "Modeling and Simulation of the Start-up of a Thorium-Based Molten Salt Reactor," Proc. Int. Conf. PHYSOR 2016, Sun Valley, ID, USA (2016).

S. M. Bowman, "SCALE 6: Comprehensive Nuclear Safety Analysis Code System,” Nuclear Technology, Vol. 174 (2011).

S. Brinton, "The Advanced Nuclear Industry," http://www.thirdway.org/report/the-advanced-nuclearindustry, June 15, 2015, accessed Mar. 1, 2016.

Brown, N. R., J. J. Powers, B. Feng, F. Heidet, N. E. Stauff, G. Zhang, M. Todosow et al. "Sustainable thorium nuclear fuel cycles: A comparison of intermediate and fast neutron spectrum systems," Nuclear Engineering and Design, 289, 252-265 (2015). 
Brown, N.R., Powers, J.J., Todosow, M., Fratoni, M., Ludewig, H., Sunny, E.E., Raitses, G. and Aronson, A., 2016. Thorium Fuel Cycles with Externally Driven Systems. Nuclear Technology, 194(2), pp.233-251. a

Brown, N.R., Carlsen, B.W., Dixon, B.W., Feng, B., Greenberg, H.R., Hays, R.D., Passerini, S., Todosow, M. and Worrall, A., 2016. Identification of fuel cycle simulator functionalities for analysis of transition to a new fuel cycle. Annals of Nuclear Energy, 96, pp.88-95. b

J. J. Bulmer et al., Fused Salt Fast Breeder: Reactor Design and Feasibility Study, CF-56-8-204, Oak Ridge School of Reactor Technology (1956).

Cammi, Antonio, Carlo Fiorina, Claudia Guerrieri, and Lelio Luzzi. "Dimensional effects in the modelling of MSR dynamics: moving on from simplified schemes of analysis to a multi-physics modelling approach." Nuclear Engineering and Design, 246 (2012): 12-26.

M. Cheng and Z. Dai, "Development of a three dimension multi-physics code for molten salt fast reactor," Nuclear Science and Techniques, 25, 010601 (2014).

M. D. DeHart and S. M. Bowman, "Reactor Physics Methods and Analysis Capabilities in SCALE," Nucl. Technol., 174(2): pp. 196-213 (2011).

X. Doligez, D. Heuer, E. Merle-Lucotte, M. Allibert, V. Ghetta, “Coupled study of the Molten Salt Fast Reactor core physics and its associated reprocessing unit," Annals of Nuclear Energy, 64:430-440 (2014).

J. J. Duderstadt and L. J. Hamilton, Nuclear Reactor Analysis, John Wiley \& Sons (1976). 
J. R. Engel et al., Conceptual Design Characteristics of a Denatured Molten-Salt Reactor with Once-Through Fueling, ORNL/TM-7207, July 1980.

Feng, B., Dixon, B., Sunny, E., Cuadra, A., Jacobson, J., Brown, N.R., Powers, J., Worrall, A., Passerini, S. and Gregg, R., 2016. Standardized verification of fuel cycle modeling. Annals of Nuclear Energy, 94, pp.300-312.

C. Fiorina, M. Aufiero, A. Cammi, M.E. Ricotti, "Investigation of the MSFR core physics and fuel cycle characteristics," Progress in Nuclear Energy, 68:153-168 (2013).

Fiorina, Carlo, et al. "Modelling and analysis of the MSFR transient behaviour." Annals of Nuclear Energy, 64 (2014): 485-498.

I. C. Gauld, G. Radulescu, G. Ilas, B. D. Murphy, M. L. Williams, and D. Wiarda, "Isotopic Depletion and Decay methods and Analysis Capabilities in SCALE," Nuclear Technology, Vol. 174, (2011).

Gehin, Jess C., and Jeffrey J. Powers. "Liquid fuel molten salt reactors for thorium utilization." Nuclear Technology 194, no. 2 (2016).

S. Goluoglu, L. M. Petrie, Jr., M. E. Dunn, D. F. Hollenbach, and B. T. Rearden, "Monte Carlo Criticality Methods and Analysis Capabilities in SCALE," Nuclear Technology, Vol. 174, (2011).

Heidet, F., Brown, N.R. and Haj Tahar, M., 2015. Accelerator-Reactor Coupling for Energy Production in Advanced Nuclear Fuel Cycles. Reviews of Accelerator Science and Technology, 8, pp.99-114. 
D. Heuer et al., "Towards the Thorium Fuel Cycle with Molten Salt Reactors", Annals of Nuclear Energy, 64, 421-429 (2014).

D. Heuer, E. Merle-Lucotte et al., 2010, "Simulation Tools and New Developments of the Molten Salt Fast Reactor," Contribution A0115, Proceedings of the European Nuclear Conference ENC2010, Barcelona, Spain.

IAEA Safeguards Glossary, 2001 Edition, International Nuclear Verification Series, No. 3.

Y. Jeong et al., "Equilibrium core design methods for molten salt breeder reactor based on two-cell model," Journal of Nuclear Science and Technology, Volume 53, Issue 4, 529-536 (2016).

C. W. Kee and L. E. McNeese, "MRPP - Multiregion Processing Plant Code,” ORNL/TM-4210, Oak Ridge National Laboratory (1976).

Kerlin, T. W., S. J. Ball, and R. C. Steffy. "Theoretical dynamics analysis of the molten-salt reactor experiment." Nuclear Technology, 10, no. 2 (1971): 118-132.

Kópházi, J., D. Lathouwers, and J. L. Kloosterman. "Development of a three-dimensional time-dependent calculation scheme for molten salt reactors and validation of the measurement data of the molten salt reactor experiment." Nuclear science and engineering, 163, no. 2 (2009): $118-131$.

Křepel, Jiř́, Ulrich Rohde, Ulrich Grundmann, and Frank-Peter Weiss. "Dynamics of molten salt reactors." Nuclear Technology, 164, no. 1 (2008): 34-44. 
Křepel, Jiř́i, Ulrich Rohde, Ulrich Grundmann, and Frank-Peter Weiss. "DYN3D-MSR spatial dynamics code for molten salt reactors." Annals of Nuclear Energy, 34, no. 6 (2007): 449-462.

Ludwig, S.B., Renier, J.P., 1989. Standard- and Extended-Burnup PWR and BWR Reactor Models for the ORIGEN2 Computer Code. Technical Report ORNL-TM-11018. Oak Ridge National Laboratory, 1989.

MCNP. A General Monte Carlo N-Particle (MCNP) Transport Code. Los Alamos National Laboratory. <menp.lanl.gov>.

MCNP6 User's Manual. LA-CP-13-000634 version 1.0. Los Alamos National Laboratory Report, 2013.

A. Mourogov and P. M. Bokov, "Potentialities of the fast spectrum molten salt reactor concept: REBUS-3700,” Energy Conversion and Management, 47, 2761-2771 (2006).

A. Nuttin, D. Heuer, A. Billebaud, R. Brissot, C. Le Brun, E. Liatard, J.-M. Loiseaux, L. Mathieu, O. Meplan, E. Merle-Lucotte, H. Nifenecker, F. Perdu, and S. David, "Potential of thorium molten salt reactorsdetailed calculations and concept evolution with a view to large scale energy production," Progress in Nuclear Energy, Volume 46, Issue 1, Pages 77-99 (2005).

J. Park et al., "Whole core analysis of molten salt breeder reactor with online fuel reprocessing," International Journal of Energy Research, Volume 39, Issue 12, 1673-1680 (2015). 
J. J. Powers, T. J. Harrison, and J. C. Gehin, “A New Approach for Modeling and Analysis of Molten Salt Reactors Using SCALE," Proc. Int. Conf. Mathematics and Computational Methods Applied to Nuclear Science and Engineering (M\&C 2013), Sun Valley, Idaho (2013).

J. J. Powers, J. C. Gehin, A. Worrall, T. J. Harrison, and E. E. Sunny, “An Inventory Analysis of Thermal-Spectrum Thorium-Fueled Molten Salt Reactor Concepts," Proc. Int. Conf. PHYSOR 2014, Kyoto, Japan (2014).

B. T. Rearden and M. A. Jessee, Eds., SCALE Code System, ORNL/TM-2005/39, Version 6.2, Oak Ridge National Laboratory, Oak Ridge, Tennessee, June 2016. Available from Radiation Safety Information Computational Center at Oak Ridge National Laboratory as CCC-834.

Rimpault, G., Plisson, D., Tommasi, J., Jacqmin, R., Rieunier, J., Verrier, D., Biron, D.,2002. The ERANOS code and data system for fast reactor neutronic analyses. In:Proc. Int. Conf. PHYSOR 2002, Seoul, Korea, October 7-10, 2002.

R. C. Robertson et al., Conceptual Design Study of a Single-Fluid Molten Salt Breeder Reactor, ORNL-4541, Union Carbide Nuclear Division, Oak Ridge National Laboratory (1971).

R. C. Robertson et al., Two-Fluid Molten-Salt Breeder Reactor Design, ORNL-4528, Oak Ridge National Laboratory August 1970.

G. van Rossum, Python tutorial, Technical Report CS-R9526, Centrum voor Wiskunde en Informatica (CWI), Amsterdam, May 1995. 
S. Sen and G. J. Youinou, Multirecycling of Plutonium from LMFBR Blanket in Standard PWRs Loaded with MOX Fuel, INL/EXT-13-28448, Idaho National Laboratory, February 2013.

Jérôme Serp, Michel Allibert, Ondrej Benes, Sylvie Delpech, Olga Feynberg, Véronique Ghetta, Daniel Heuer, David Holcomb, Victor Ignatiev, Jan Leen Kloosterman, Lelio Luzzi, Elsa Merle-Lucotte, Jan Uhlír, Ritsuo Yoshioka, Dai Zhimin, “The molten salt reactor (MSR) in generation IV: Overview and perspectives," Progress in Nuclear Energy, 77, 308-319 (2014).

SERPENT, PSG2 / Serpent Monte Carlo Reactor Physics Burnup CalculationCode, 2011. $<$ http://montecarlo.vtt.fi $>$.

R.J. Sheu, C.H. Chang, C.C. Chao, Y.-W.H. Liu, "Depletion analysis on long-term operation of the conceptual Molten Salt Actinide Recycler \& Transmuter (MOSART) by using a special sequence based on SCALE6/TRITON," Annals of Nuclear Energy, Volume 53, Pages 1-8 (2013).

Shi, Chengbin, Maosong Cheng, and Guimin Liu. "Development and application of a system analysis code for liquid fueled molten salt reactors based on RELAP5 code." Nuclear Engineering and Design, 305 (2016): 378-388.

Shimazu, Yoichiro. "Nuclear safety analysis of a molten salt breeder reactor." Journal of Nuclear Science and Technology, 15, no. 7 (1978): 514-522.

J. Smith and W. E. Simmons, An Assessment of a 2500MWe Molten Chloride Salt Fast Reactor, AEEW-R 956, United Kingdom Atomic Energy Authority (1974). 
Stauff, N.E., Kim, T.K. and Taiwo, T.A., 2015. Variations in nuclear waste man-agement performance of various fuel-cycle options. Journal of Nuclear Science and Technology, 52(7-8), pp.1058-1073.

M. Taube, A Molten Salt Fast Thermal Reactor System with no Waste, EIR-Bericht Nr. 249, Eidg. Institut für Reaktorforschung Würenlingen Schweiz, January 1974.

M. Taube and J. Ligou, "Molten Plutonium Chloride Fast Breeder Reactor Cooled by Molten Uranium Chloride," Annals of Nuclear Science and Engineering, 1, 277-281 (1974).

B. J. Toppel, “A User's Guide to the REBUS-3 Fuel Cycle Analysis Capability,” ANL-83-2, Argonne National Laboratory (1983).

US DOE, "Gateway for Accelerated Innovation in Nuclear," http://energy.gov/technologytransitions/gateway-accelerated-innovation-nuclear, accessed Aug. 8, 2016, Nov. 2015 (2015).

US DOE, "Gateway for Accelerated Innovation in Nuclear," http://www.energy.gov/articles/energy-department-announces-new-investments-advanced-nuclear-p ower-reactors-help-meet, accessed Aug. 8, 2016, Jan. 15, 2016 (2016).

White House, Office of the Press Secretary, "FACT SHEET: Obama Administration Announces Actions to Ensure that Nuclear Energy Remains a Vibrant Component of the United States' Clean Energy Strategy," https://www.whitehouse.gov/the-press-office/2015/11/06/fact-sheet-obama-administration-announc es-actions-ensure-nuclear-energy, accessed Aug. 8, 2016, Nov. 6 (2015). 
R. Wigeland et al., Nuclear Fuel Cycle Evaluation and Screening - Final Report, INL/EXT-14-31465, Idaho National Laboratory (2014).

Xu, Zhiwen et al., 2002, “An Improved MCNP-ORIGEN Depletion Program (MCODE) and its Verification for High Burnup Applications" PHYSOR, Seoul, Korea.

Zhou, Jianjun, Daling Zhang, Suizheng Qiu, Guanghui Su, Wenxi Tian, and Yingwei Wu. "Three dimensional neutronic/thermal-hydraulic coupled simulation of MSR in transient state condition." Nuclear Engineering and Design, 282 (2015): 93-105. 